\title{
Monaural and Binaural Inhibition Underlying Duration-Tuned Neurons in the Inferior Colliculus
}

\author{
Riziq Sayegh, ${ }^{1}$ John H. Casseday, ${ }^{2}$ Ellen Covey, ${ }^{2}$ and Paul A. Faure ${ }^{1}$ \\ ${ }^{1}$ Department of Psychology, Neuroscience \& Behaviour, McMaster University, Hamilton, Ontario L8S 4K1, Canada, and 2Department of Psychology, \\ University of Washington, Seattle, Washington 98195-1525
}

\begin{abstract}
Duration-tuned neurons (DTNs) in the mammalian inferior colliculus (IC) arise from a combination of excitatory and inhibitory synaptic inputs. Previous research has shown that the inhibition responsible for creating DTNs has a shorter latency than that of excitation and lasts longer than the stimulus duration. We used monotic and dichotic paired tone stimulation and recorded responses of DTNs from the IC of the bat to assess the relative contributions of each ear in forming duration-tuned circuits. The stimulus consisted of a short best duration (BD) excitatory tone and a longer duration nonexcitatory (NE) tone. In the monotic condition, when the BD and NE tones were presented to the contralateral ear and were sufficiently close in time, the NE tone always suppressed spikes evoked by the BD tone. In the dichotic condition, when the BD tone was presented to the contralateral ear and the NE tone to the ipsilateral ear, half of DTNs no longer showed spike suppression to the NE tone. Of those DTNs with suppression in both conditions, the latency of the inhibition was shorter and the duration of the inhibition was longer in the monotic condition. Therefore, in the monotic condition, DTNs received a contralaterally evoked inhibitory input that preceded the excitatory input to the same neuron. In the dichotic condition, DTNs received an ipsilaterally evoked inhibitory input that was weaker, longer in latency, and shorter in duration than the inputs from the contralateral ear. These findings indicate that the neural mechanisms that create DTNs in the IC are monaural.
\end{abstract}

Key words: audition; auditory midbrain; big brown bat (Eptesicus fuscus); hearing; paired tone stimulation; temporal masking

\section{Introduction}

The auditory midbrain or inferior colliculus (IC) is the first nucleus in the central auditory pathway that contains neurons with duration-selective responses. These duration-tuned neurons (DTNs) are found in the IC and auditory cortex in a variety of vertebrates. Although DTNs have been primarily studied in bats and are likely important for echolocation, they have also been reported from the auditory midbrain of non-echolocating amphibians and mammals (for review, see Sayegh et al., 2011). Therefore, the role of DTNs in normal hearing cannot be exclusive for echolocation. Although their exact functions are unknown, DTNs provide a potential neural mechanism for processing temporal features of sound in human speech (Denes, 1955 ) and species-specific communication sounds (Pollack and Hoy, 1979; Bohn et al., 2008; Gadziola et al., 2012).

Received Aug. 30, 2013; revised 0ct. 25, 2013; accepted Nov. 16, 2013.

Author contributions: J.H.C., E.C., and P.A.F. designed research; R.S. and P.A.F. performed research; R.S. and P.A.F. analyzed data; R.S. and P.A.F. wrote the paper.

This work was supported by National Institutes of Health Research Grants DC-00287 (J.H.C.) and DC-00607 (E.C.) National Institute on Deafness and Other Communication Disorders Research Core Center Grant DC-04661, and a Discovery Grant from the Natural Sciences and Engineering Research Council of Canada (P.A.F.). R.S. was supported by an Ontario Graduate Scholarship. The McMaster Bat Laboratory was also supported by infrastructure grants from the Canada Foundation for Innovation and the Ontario Innovation Trust. We thank Appalachia Martine and Kimberly Miller for technical assistance, Brandon Warren and Brandon Aubie for custom programming, and Thane Fremouw for assistance with data collection.

The authors declare no competing financial interests.

Correspondence should be addressed to Paul A. Faure, Department of Psychology, Neuroscience \& Behaviour, McMaster University, 1280 Main Street West, Hamilton, Ontario L8S 4K1, Canada. E-mail: paul4@mcmaster.ca.

DOI:10.1523/JNEUROSCI.3732-13.2014

Copyright $\odot 2014$ the authors $\quad 0270-6474 / 14 / 340481-12 \$ 15.00 / 0$
Intracellular (Covey et al., 1996; Tan and Borst, 2007; Leary et al., 2008) and extracellular (Casseday et al., 1994, 2000; Ehrlich et al., 1997; Chen, 1998; Faure et al., 2003) recordings from DTNs have led to conceptual models of the neural mechanism(s) responsible for duration selectivity based on the interaction of excitatory and inhibitory synaptic inputs offset in time (Casseday et al., 1994, 2000; Fuzessery and Hall, 1999; Sayegh et al., 2011). Indeed, computational models of these mechanisms can reproduce the in vivo spiking responses of DTNs in both echolocating bats and non-echolocating vertebrates (Aubie et al., 2009, 2012).

Paired tone stimulation combined with single-unit extracellular recording has been used previously to characterize the strength and time course of inhibitory inputs to DTNs (Faure et al., 2003). These experiments were conducted with monotic stimulation to the contralateral ear. To characterize the relative contributions of each ear in forming and modifying durationselective responses, we used monotic and dichotic paired tone stimulation, with one excitatory tone set to the best duration (BD) of the neuron and another tone set to a longer, nonexcitatory (NE) duration. In both conditions, the BD tone was presented to the contralateral ear. In the monotic condition, the $\mathrm{NE}$ tone was also presented to the contralateral (excitatory) ear, whereas in the dichotic condition, the NE tone was presented to the ipsilateral (inhibitory) ear. Using this stimulus paradigm, we found that monotic paired tone stimulation always caused spike suppression in DTNs via sustained inhibition evoked by the NE tone; however, during dichotic paired tone stimulation, approximately half of the cells were not suppressed by the NE tone. We 
expected to see a greater inhibitory effect in the dichotic condition because ipsilateral ear stimulation typically suppresses contralaterally evoked spikes of IC neurons (Hind et al., 1963; Rose et al., 1966). For those DTNs with binaural inhibition, the inhibition evoked in the dichotic condition was weaker in strength, shorter in duration, and delayed relative to the inhibition evoked monaurally. Altogether, these results support the conclusion that the underlying neural mechanisms that create DTNs in the mammalian IC are primarily monaural.

\section{Materials and Methods}

Surgical procedures. Methods for surgical procedures and electrophysiological recordings have been described previously (Faure et al., 2003; Aubie et al., 2012; Sayegh et al., 2012). Briefly, electrophysiological recordings were obtained from 15 big brown bats (Eptesicus fuscus) of both sexes at the University of Washington and McMaster University. To facilitate multiple recordings from individual animals and to precisely replicate the position of the bat's head between recording sessions, a stainless steel post was glued to the skull. Before surgery, bats were given a subcutaneous injection of buprenorphine $(0.03 \mathrm{ml} ; 0.025 \mathrm{mg} / \mathrm{kg})$. For surgery, bats were first placed in an anesthesia induction chamber $(12 \times$ $10 \times 10 \mathrm{~cm})$ where they inhaled a $1-5 \%$ isoflurane/oxygen mixture $(1$ $\mathrm{L} / \mathrm{min}$ ). Anesthetized bats were then placed in a foam-lined body restraint within a model 1900 stereotaxic alignment system with a custom bite bar and gas mask (David Kopf Instruments) for continuous isoflurane inhalation. The hair covering the skull was cropped and the skin disinfected with Betadine surgical scrub. Local anesthetic $(0.2 \mathrm{ml}$ of bupivicaine; $5 \mathrm{mg} / \mathrm{ml}$ ) was injected subcutaneously before making a midline incision in the scalp. The temporal muscles were reflected, the skull was scraped clean and swabbed with $70-100 \%$ ethanol, and a post was glued to the skull overlying the cortex with cyanoacrylate adhesive (Loctite; Henkel) cured with liquid acrylic hardener (Zipkicker; Pacer Technology). A chlorided silver wire attached to the head post was placed under the temporal muscles and served as the reference electrode. Recordings began 1-4 d after surgery. Each bat was used in one to eight sessions lasting 6-8 h each. Recordings were terminated if a bat showed signs of discomfort. Between sessions, the electrode penetration site was covered with a piece of contact lens and Gelfoam coated in Polysporin. Bats were housed individually in a temperature- and humidity-controlled room. All procedures were approved by the University of Washington Laboratory Animal Care and Use Committee or the McMaster University Animal Research Ethics Board and were in accordance with guidelines published by the National Institutes of Health and the Canadian Council on Animal Care.

Electrophysiological recordings. Electrophysiological recordings were conducted inside a double-walled, sound-attenuating booth with electrical shielding (Industrial Acoustics). Before recording, each bat was given a subcutaneous injection of neuroleptic $(0.3 \mathrm{ml} ; 1: 1$ mixture of 0.05 $\mathrm{mg} / \mathrm{ml}$ fentanyl citrate and $2.5 \mathrm{mg} / \mathrm{ml}$ droperidol; $19.1 \mathrm{mg} / \mathrm{kg}$ ). Bats were then placed in a foam-lined body restraint that was suspended by springs within a small animal stereotaxic frame customized for bats (ASI Instruments) and mounted atop an air vibration table (TMC Micro-g). The bat's head was immobilized by securing the head post to a stainless steel rod attached to a micromanipulator (ASI Instruments) mounted on the stereotaxic frame. The dorsal surface of the IC was exposed for recording by making a small opening in the skull and dura mater with a scalpel. Single-unit extracellular recordings were made with thin-wall borosilicate glass microelectrodes with a capillary filament ( $1.2 \mathrm{~mm}$ outer diameter; A-M Systems) and filled with $0.3-3 \mathrm{M} \mathrm{NaCl}$ or physiological saline. Typical electrode resistances ranged from 10 to $30 \mathrm{M} \Omega$. Electrodes were manually positioned over the dorsal surface of the IC with a manipulator (ASI Instruments) and advanced into the brain with a stepping hydraulic micropositioner (model 2650; David Kopf Instruments). Action potentials were recorded with a Neuroprobe amplifier (model 1600; A-M Systems), the $10 \times$ output of which was bandpass filtered and further amplified $(500-1000 \times)$ by a Tucker Davis Technologies (TDT) spike preconditioner (TDT PC1; low-pass $f_{c}=7 \mathrm{kHz}$; high-pass $f_{c}=300 \mathrm{~Hz}$ ). Spike times were logged on a computer by passing the PC1 output to a spike discriminator (TDT SD1) and then an event timer (TDT ET1) synchronized to a timing generator (TDT TG6).

Stimulus generation. Stimulus generation and online data collection were controlled with custom software that displayed spike times as peristimulus dot raster displays (rastergrams) ordered by the acoustic parameter that was varied (Faure et al., 2003). Sound pulses were digitally generated with a two-channel array processor (TDT Apos II; $357 \mathrm{kHz}$ sampling rate) optically interfaced to two digital-to-analog converters (TDT DA3-2) whose individual outputs were fed to a two-channel lowpass anti-aliasing filter (TDT FT6-2; $f_{c}=120 \mathrm{kHz}$ ), two programmable attenuators (TDT PA5), and two signal mixers (TDT SM5) with equal weighting. The output of each mixer was fed to a manual attenuator (Leader LAT-45) before final amplification (model 7500; Krohn-Hite). Auditory stimuli were presented via a pair of Brüel \& Kjær one-quarterinch condenser microphones (type 4939; protective grid on), modified for use as loudspeakers with a transmitting adaptor (type UA-9020; Brüel \& Kjær) to correct for nonlinearities in the transfer function (Frederiksen, 1977). Each loudspeaker was positioned $\sim 1 \mathrm{~mm}$ in front of the external auditory meatus. The output of each speaker, measured with a Brüel \& Kjær type 4138 one-eighth-inch condenser microphone $\left(90^{\circ}\right.$ incidence; grid off) connected to a measuring amplifier (type 2606; Brüel \& Kjær) and bandpass filter (model 3500; Krohn-Hite), was quantified with a sound calibrator (type 4231; Brüel \& Kjær) and expressed in decibels sound pressure level ( $\mathrm{dB}$ SPL relative to $20 \mu \mathrm{Pa}$ ) equivalent to the peak amplitude of continuous tones of the same carrier frequency. The loudspeaker transfer function was flat $\pm 6 \mathrm{~dB}$ from 28 to $118 \mathrm{kHz}$, and there was at least $30 \mathrm{~dB}$ attenuation at the ear opposite the source (Ehrlich et al., 1997). All stimuli had rise/fall times of $0.4 \mathrm{~ms}$ shaped with a square cosine function and were presented at a rate of $3 \mathrm{~Hz}$. Search stimuli were presented monaurally, contralateral to the IC being recorded. Single units were found by presenting short-duration pure tones and/or downward frequency modulated sweeps. During unit isolation, we determined the characteristic frequency, minimum threshold, and first-spike latency (relative to signal onset) for each cell, and for DTNs, we also determined the $\mathrm{BD}$ and filter response class (for definitions, see Faure et al., 2003; Fremouw et al., 2005; i.e., short-pass, bandpass, or long-pass DTN).

Following the paired tone stimulation paradigms of Faure et al. (2003) and Covey and Faure (2005), we presented DTNs with pairs of characteristic frequency tones that differed in duration and interstimulus inter$\mathrm{val}$ (ISI). One tone in the pair was used as a probe and was set to the $\mathrm{BD}$ (BD tone; $D_{\mathrm{BD}}$ ); the other was as $\mathrm{NE}$ tone set to a longer duration that did not evoke spikes (NE tone; $D_{\mathrm{NE}}$ ). The duration of the NE tone was typically set to $10 \times$ the duration of the $\mathrm{BD}$ tone. The onset time of the NE tone was fixed between trials, whereas the onset time of the BD tone was randomly varied in $2 \mathrm{~ms}$ steps. Unless stated otherwise, the BD and NE tones were matched in frequency, amplitude, and phase at all ISIs. The frequency of the $\mathrm{BD}$ and $\mathrm{NE}$ tones was set to the characteristic frequency of the cell. The amplitude of the $\mathrm{BD}$ tone was typically set to $+10 \mathrm{~dB}$ (relative to threshold), and the amplitude of the NE tone was set to +0 , +10 , or $+20 \mathrm{~dB}$ (relative to $\mathrm{BD}$ tone). Because the $\mathrm{BD}$ and NE tones were matched in frequency and phase, whenever the tones overlapped they summed to form a single composite tone with a $+6 \mathrm{~dB}$ amplitude pedestal, the duration of which was determined by the amount of temporal overlap.

Determining the time course of inhibition. For each cell, we measured the latency and duration of the inhibition evoked by the stationary NE tone during monotic and dichotic paired tone stimulation by observing the times when spikes evoked by the roving $\mathrm{BD}$ tone were suppressed and/or altered in latency. In both conditions, the $\mathrm{BD}$ tone was presented to the contralateral (excitatory) ear. In the monotic condition, the NE tone was electronically mixed and also presented to the contralateral ear, whereas in the dichotic condition, the NE tone was split and presented to the ipsilateral (inhibitory) ear while the BD tone was presented to the contralateral (excitatory) ear. In this way, we were able to measure and compare the net inhibition evoked by the NE tone through the monaural and binaural central auditory pathways.

Figure 1 is an example of spiking responses evoked from a bandpass DTN tested with monotic (monaural) paired tone stimulation using 
A

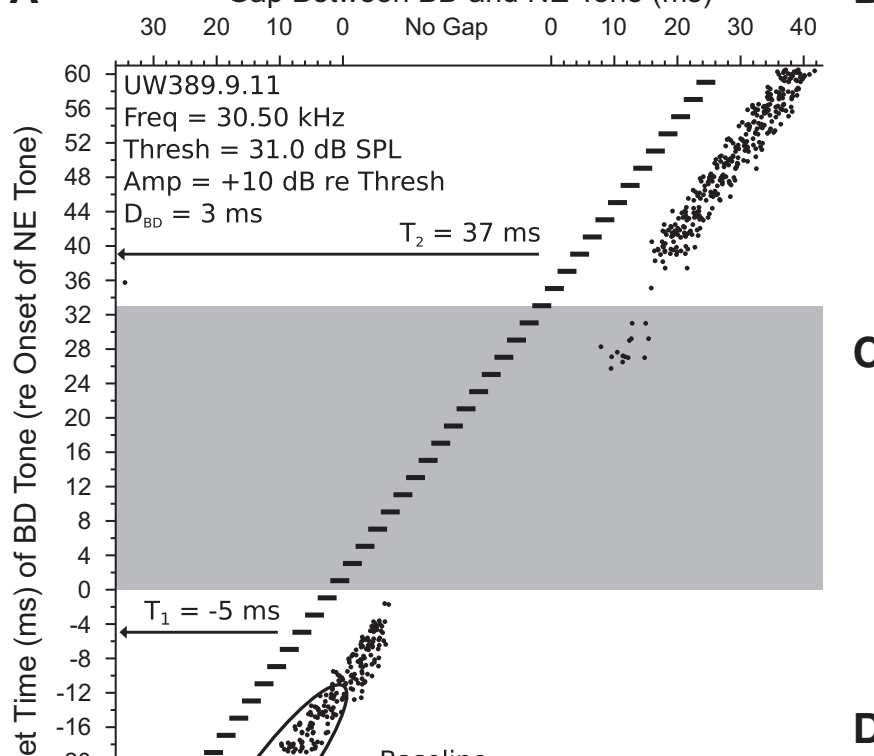

BD Tone (Contra) NE Tone (Contra)

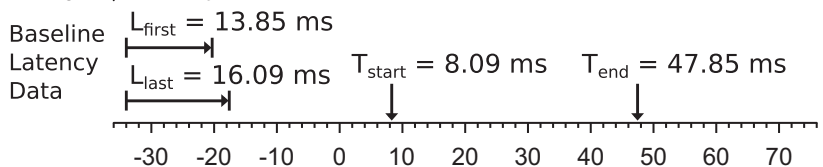

Offset Time (ms) of BD Tone (re Onset of NE Tone)

$$
\mathrm{T}_{\text {start }}=\mathrm{T}_{1}+\mathrm{L}_{\text {last }}-\mathrm{D}_{\mathrm{BD}} \quad \mathrm{T}_{\text {end }}=\mathrm{T}_{2}+\mathrm{L}_{\text {first }}-\mathrm{D}_{\mathrm{BD}}
$$

B

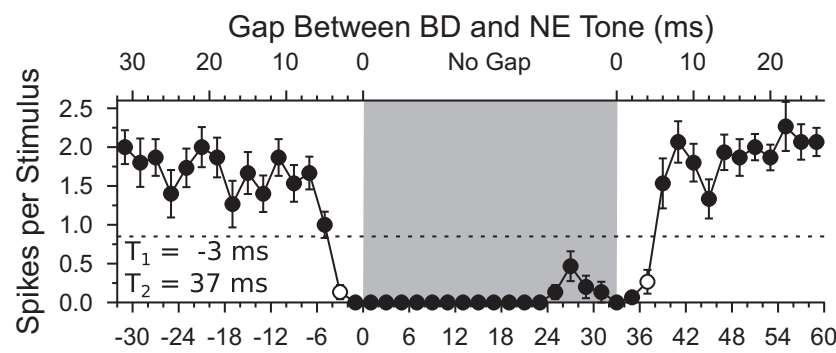

C

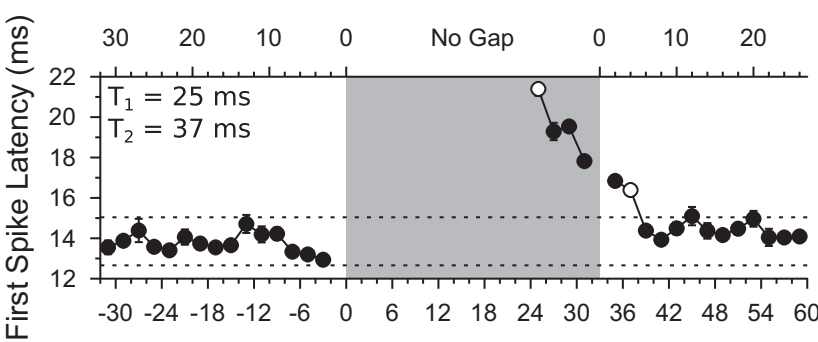

D

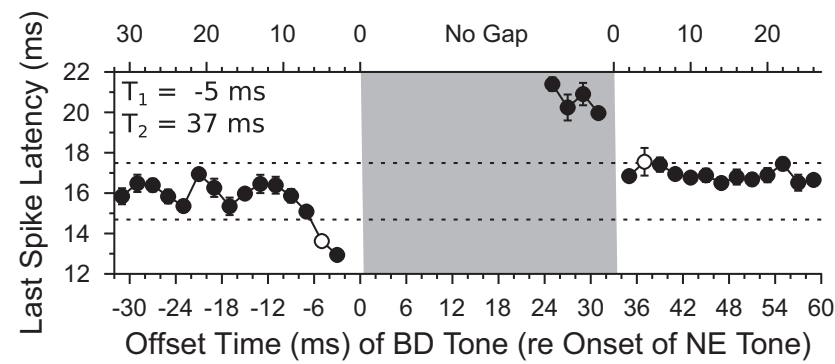

Figure 1. Measuring the time course of inhibition with paired tone stimulation. $A$, Dot raster display illustrating how changes in the number and timing of action potentials were used to calculate the $T_{1}$ and $T_{2}$ of the inhibition evoked by the NE tone using the equations given at the bottom. The BD and NE tones are illustrated with black bars, short bars represent the roving 3 ms BD tone, and a single long bar represents the stationary $30 \mathrm{~ms} N E$ tone. On each trial, the cell was presented with a BD and NE tone that were randomly varied in ISI (for clarity, the NE tone is drawn only once). There were 15 stimulus repetitions per ISI tested. The gray box indicates the range of times over which the BD and NE tones were temporally contiguous or overlapping. Note the gap in the response of the cell when the BD and NE tones were sufficiently close in time. Circled responses are the 10 trials that were used to calculate the mean \pm SD baseline spike count (1.70 \pm 1.02 spikes per stimulus), baseline FSL $\left(L_{\text {first }}=13.85 \pm 1.19 \mathrm{~ms}\right.$ relative to $B D$ tone onset), and the baseline $L S L\left(L_{\text {last }}=16.09 \pm 1.40 \mathrm{~ms}\right.$ relative to BD tone onset). For this cell, the first ISI with a significant deviation from the baseline spike count or latency was $T_{1}=-5 \mathrm{~ms}$ (determined by $\mathrm{LSL}$ ), and the longest ISI with a significant deviation from the baseline spike count or latency was $T_{2}=37 \mathrm{~ms}$ (consensus from all measures). The calculated inhibition $T_{\text {start }}=8.09 \mathrm{~ms}$ and the inhibition $T_{\text {end }}=47.85 \mathrm{~ms}$, resulting in an effective duration of inhibition of $39.76 \mathrm{~ms}$. The cell had $5.76 \mathrm{~ms}$ of leading inhibition and $9.76 \mathrm{~ms}$ of persistent inhibition (see Materials and Methods). $\boldsymbol{B}$, Mean \pm SE spikes per stimulus as a function of the offset of the BD tone relative to the onset of the NE tone. The dotted line represents $50 \%$ of the baseline spike count. The leftmost open circle is the first ISI in which the spike count dropped to $\leq 50 \%$ of baseline with a consecutive data point also $\leq 50 \%$ of baseline; this point represents the onset of spike suppression measured with spike counts $\left(T_{1}=-3 \mathrm{~ms}\right)$. The rightmost open circle represents the longest $I S I$, starting from $T_{1}$, in which the spike count was still $\leq 50 \%$ of baseline and with the two next consecutive data points $>50 \%$ of baseline; this point represents the offset of spike suppression measured with spike counts ( $T_{2}=37$ ms). C, Mean \pm SE FSL as a function of the offset of the BD tone relative to the onset of the NE tone. Dotted lines represent \pm 1 SD relative to baseline FSL. The leftmost open circle is the first ISI with a FSL that deviated by $>1$ SD from baseline with a consecutive data point also $>1$ SD from baseline; this point represents the onset of spike suppression measured with FSL ( $\left.T_{1}=25 \mathrm{~ms}\right)$. The rightmost open circle is the longest $|S|$, starting from $T_{1}$, in which the FSL deviated by $>1 \mathrm{SD}$ from baseline with the two next consecutive data points within 1 SD of baseline; this point represents the offset of spike suppression measured with FSL $\left(T_{2}=37 \mathrm{~ms}\right)$. $D$, Mean $\pm S E L S L$ as a function of the offset of the BD tone relative to the onset of the NE tone. Dotted lines represent \pm 1 SD relative to baseline LSL. The leftmost open circle is the first ISI with a LSL that deviated by $>1$ SD from baseline with a consecutive data point also $>1$ SD from baseline; this point represents the onset of spike suppression measured with $\mathrm{LSL}\left(T_{1}=-5 \mathrm{~ms}\right)$. The rightmost open circle is the longest $\mid \mathrm{SI}$, starting from $T_{1}$, in which the FSL deviated by $>1 \mathrm{SD}$ from baseline with the two next consecutive data points within 1 SD of baseline; this point represents the offset of spike suppression measured with LSL ( $T_{2}=37 \mathrm{~ms}$ ). Amp, Amplitude; Contra, contralateral; Freq, frequency; Thresh, threshold.

equal-amplitude BD and NE tones. Also illustrated are details of how we measured the onset $\left(T_{1}\right)$ and offset $\left(T_{2}\right)$ of spike suppression using changes in the spike count, first spike latency (FSL), and/or last spike latency (LSL) of the cell. Note the suppression in spiking when the BD and NE tones were presented at sufficiently small ISIs. The circled responses represent the 10 trials with the largest ISIs, when the $\mathrm{BD}$ tone preceded the NE tone, that were used to calculate the mean \pm SD baseline spike count and baseline FSL and LSL (Fig. 1A). For this cell, the baseline spike count was $1.70 \pm 1.02$ spikes per stimulus, the baseline FSL $\left(L_{\text {first }}\right)$ was $13.85 \pm 1.19 \mathrm{~ms}$ (relative to BD tone onset), and the baseline LSL $\left(L_{\text {last }}\right)$ was $16.09 \pm 1.40 \mathrm{~ms}$ (relative to $\mathrm{BD}$ tone onset).

For each cell, we plotted the average spike count, FSL, and LSL as a function of the gap between the offset of the BD tone and the onset of the NE tone (Fig. $1 B-D$ ). We then used changes in the evoked response to measure the onset (latency) and time course (duration) of spike suppression, and thus the neural inhibition, evoked by the NE tone. Starting from the largest ISI when the BD tone preceded the NE tone, the onset $\left(T_{1}\right)$ of spike suppression was defined to be the first data point at which the spike count decreased to $\leq 50 \%$ of the baseline count (or the spike latency increased or decreased by $>1$ SD from the baseline latency) as long as the following data point also remained $\leq 50 \%$ (or $>1 \mathrm{SD}$ ) from baseline (Sayegh et al., 2012). The offset $\left(T_{2}\right)$ of spike suppression was defined to be the longest ISI, starting from $T_{1}$ and moving toward ISIs when the BD tone followed the NE tone, in which the spike count (or latency) remained $\leq 50 \%$ (or deviated by $>1 \mathrm{SD}$ ) from baseline if the two consecutive data points were $>50 \%$ (or within \pm 1 SD) of baseline. Using spike count criteria on the bandpass DTN in Figure 1, the onset and offset times of spike suppression were $T_{1}=-3 \mathrm{~ms}$ and $T_{2}=37 \mathrm{~ms}$, respectively 
(Fig. 1B). Using spike latency criteria, the onset and offset times of spike suppression measured with FSL changes were $T_{1}=25 \mathrm{~ms}$ and $T_{2}=37$ $\mathrm{ms}$, respectively (Fig. 1C), whereas using LSL changes, they were $T_{1}=-5$ $\mathrm{ms}$ and $T_{2}=37 \mathrm{~ms}$, respectively (Fig. $1 D$ ).

The final values for $T_{1}$ and $T_{2}$ were chosen using the most sensitive criteria that reflected the time course of spike suppression (see below, Comparing inhibition measured with spike counts and latencies). For the bandpass DTN in Figure 1, the final value for $T_{1}$ was $-5 \mathrm{~ms}$ and was chosen from the LSL measure, and the final value for $T_{2}$ was $-37 \mathrm{~ms}$ because there was consensus across the spike count and latency measures. After selecting these values, the effective start $\left(T_{\text {start }}\right)$ and end $\left(T_{\text {end }}\right)$ times of the neural inhibition evoked by the NE tone were calculated as follows:

$$
T_{\text {start }}=T_{1}+L_{\text {last }}-D_{\mathrm{BD}}
$$

and

$$
T_{\text {end }}=T_{2}+L_{\text {first }}-D_{\mathrm{BD}} \text {, }
$$

where $L_{\text {last }}$ was the baseline LSL, $L_{\text {first }}$ was the baseline FSL, and $D_{\mathrm{BD}}$ was the duration of the $\mathrm{BD}$ tone. The effective duration of inhibition was calculated as $T_{\text {end }}-T_{\text {start }}$.

A neuron was said to have leading inhibition when the latency of the inhibition evoked by the NE tone was less than the excitatory FSL of the cell (i.e., $T_{\text {start }}<L_{\text {first }}$ ). A neuron was said to have persistent inhibition when the effective duration of the inhibition evoked by the NE tone was greater than the duration of the NE tone (i.e., $T_{\text {end }}-T_{\text {start }}>D_{\mathrm{NE}}$ ). For the bandpass neuron in Figure $1, T_{\text {start }}=8.09 \mathrm{~ms}$ and $T_{\text {end }}=47.85 \mathrm{~ms}$, resulting in an effective duration of inhibition of $39.76 \mathrm{~ms}$. This cell had $5.76 \mathrm{~ms}$ of leading inhibition because the latency of the inhibition evoked by the NE tone ( $\left.T_{\text {start }}=8.09 \mathrm{~ms}\right)$ was shorter than the excitatory baseline FSL of the cell $\left(L_{\text {first }}=13.85 \mathrm{~ms}\right)$. The cell also had persistent inhibition because the effective duration of the inhibition ( $T_{\text {end }}-T_{\text {start }}=39.76 \mathrm{~ms}$ ) was $9.76 \mathrm{~ms}$ longer than the duration of the NE tone $\left(D_{\mathrm{NE}}=30 \mathrm{~ms}\right)$.

Comparing inhibition measured with spike counts and latencies. The final values for $T_{1}$ and $T_{2}$ could be chosen from a combination of spike count and latency measures because doing so increased the sensitivity for quantifying the suppressive effects of the NE tone on the spiking responses evoked by the BD tone (Faure et al., 2003; Sayegh et al., 2012). In cases in which cells responded with only a single spike per stimulus (i.e., $L_{\text {first }}=L_{\text {last }}$ ) or in instances in which the spike count of the cell was clearly suppressed although $L_{\text {first }}$ or $L_{\text {last }}$ (or both) remained within \pm 1 SD of baseline, a change in spike count was typically used for selecting $T_{1}$ and $T_{2}$ because this criterion was usually more sensitive in reflecting the time course of the suppression. In cases in which cells responded with more than one spike per stimulus or in instances in which the spike count of the cell had recovered to within $50 \%$ of baseline although $L_{\text {first }}$ or $L_{\text {last }}$ (or both) were still clearly deviated by $>1$ SD from baseline, a change in spike latency was typically used for selecting $T_{1}$ and $T_{2}$ because this criterion was usually more sensitive in reflecting the time course of the suppression. In cases in which the mean spike count or latency had not returned to within $50 \%$ or \pm 1 SD of baseline, respectively, over the range of ISIs presented (monotic condition, $n=10$ cells; dichotic condition, $n=0$ cells), $T_{2}$ was conservatively estimated as the longest ISI tested.

In the monotic paired tone stimulation condition, there was consensus between spike count and spike latency criteria for the final value of $T_{1}$ in 17 of 42 cells ( $40.4 \%)$. In the remaining 25 cells, spike counts were used in 17 cases and spike latencies were used in eight cases (seven with LSL and one with FSL). The mean \pm SD spike count for the 17 cells analyzed with a spike count criterion was $1.17 \pm 0.42$ spikes per stimulus, and for the eight cells analyzed with a spike latency criterion, it was $1.88 \pm 0.63$ spikes per stimulus; spike counts in these two groups were significantly different (Mann-Whitney $U=120.00, p=0.01$ ). For the final value of $T_{2}$, there was agreement between spike count and spike latency criteria for 5 of 42 cells ( $11.9 \%$ ). In the remaining 37 cells, spike counts were used in 20 cases, and spike latencies were used in 17 cases (14 with FSL and three with LSL). The mean \pm SD spike count for the 20 cells analyzed with a spike count criterion was $1.14 \pm 0.39$ spikes per stimulus, and for the 17 cells analyzed with a spike latency criterion, it was $1.84 \pm 0.58$ spikes per stimulus; spike counts in these two groups were also significantly different $\left(t_{(35)}=-4.319, p \ll 0.001\right)$.

In the dichotic condition, there was consensus between spike count and spike latency criteria for the final $T_{1}$ value in 3 of 20 cells (15.0\%). In the remaining 17 cells, spike counts were used in nine cases, and spike latencies were used in eight cases (three with LSL, four with FSL, and one consensus). The mean \pm SD spike count for the nine cells analyzed with a spike count criterion was $1.29 \pm 0.51$ spikes per stimulus, and for the eight cells analyzed with a spike latency criterion, it was $2.27 \pm 0.69$ spikes per stimulus; spike counts in these two groups were significantly different (Mann-Whitney $U=62.00, p=0.011$ ). For the final value of $T_{2}$, spike count and spike latency criteria were in agreement for 5 of 20 cells $(25.0 \%)$. In the remaining 15 cells, spike counts were used in five cases and spike latencies were used in 10 cases (eight with FSL, one with $\mathrm{LSL}$, and one consensus). The mean \pm SD spike count for the five cells analyzed with a spike count criterion was $1.44 \pm 0.65$ spikes per stimulus, and for the 10 cells analyzed with a spike latency criterion, it was $1.63 \pm$ 0.76 spikes per stimulus; spike counts in these two groups were not significantly different (Mann-Whitney $U=27.00, p=1.00$ ).

We compared the effective duration of inhibition $\left(T_{\text {end }}-T_{\text {start }}\right)$ measured with spike counts and spike latencies in 37 DTNs tested with monotic paired tone stimulation. The mean \pm SD effective duration of inhibition was $37.13 \pm 15.15 \mathrm{~ms}$ when measured with spike counts and $33.89 \pm 15.58 \mathrm{~ms}$ when measured with spike latencies. The difference between the two measures was not statistically significant (Wilcoxon's signed-rank test, $Z=-1.241, p=0.214$ ). This analysis validates that changes in spike counts or latencies can be used to quantify the time course of spike suppression evoked by the NE tone.

Data analyses. Unless stated otherwise, all data are reported as the mean \pm SE. Data were tested for normality and homogeneity of variances with Shapiro-Wilk's and Levene's tests, respectively, before additional statistical analyses. Parametric tests were used when data were normally distributed with equal variances; otherwise, an equivalent nonparametric test was used. The proportion of DTNs with measurable inhibition in the monotic and dichotic paired tone conditions was compared with a Fisher's exact test. Two-sample $t$ tests or Mann-Whitney $U$ tests were used to compare evoked spike counts between cells in which the timing of suppression was measured with spike count or spike latency criteria. The latency and time course of the inhibition evoked in the monotic and dichotic conditions, and the durations of inhibition measured with spike counts and latencies, were compared with paired $t$ tests or Wilcoxon's signed-rank tests. Linear regressions were calculated to evaluate the relationship of BD, FSL, and leading/lagging inhibition. The effect of increasing the amplitude of the NE tone in the dichotic condition was evaluated with a Friedman's test. All statistical analyses were performed in SPSS or Python (SciPy) and used an experiment-wise error rate of $\alpha=0.05$.

\section{Results \\ Inhibition evoked with monotic and dichotic paired tone stimulation}

Figure 2 shows an example of responses evoked from a short-pass DTN tested with monotic and dichotic paired tone stimulation using equal-amplitude BD and NE tones. In this cell, spike suppression was observed for the monotic condition but was absent for the dichotic condition. In the monotic condition, when the 1 $\mathrm{ms} \mathrm{BD}$ tone and the $10 \mathrm{~ms} \mathrm{NE}$ tone were broadcast to the contralateral ear (Fig. $2 A$ ), there was a pronounced reduction in the spike count (Fig. 2B) and a significant deviation in both the FSL and LSL (Fig. 2C,D). The final value for $T_{1}$ was $1 \mathrm{~ms}$ and was derived from a change in spike count; the final value for $T_{2}$ was 49 $\mathrm{ms}$ and was derived from a change in FSL. The effective duration of spike suppression was calculated to be $47.21 \mathrm{~ms}$. Note that this neuron did not show leading inhibition because $L_{\text {first }}=8.81 \mathrm{~ms}$ and $T_{\text {start }}=9.60 \mathrm{~ms}$, thus inhibition lagged excitation by $0.79 \mathrm{~ms}$; however, it may be that the excitatory and inhibitory inputs to this cell were coincident because the difference in latency between 
Monotic

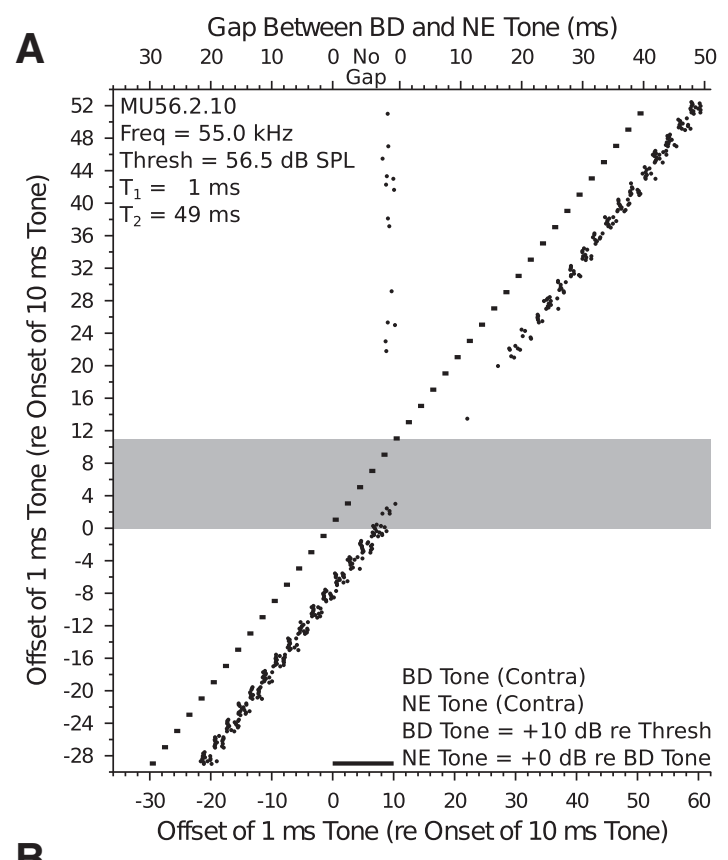

B
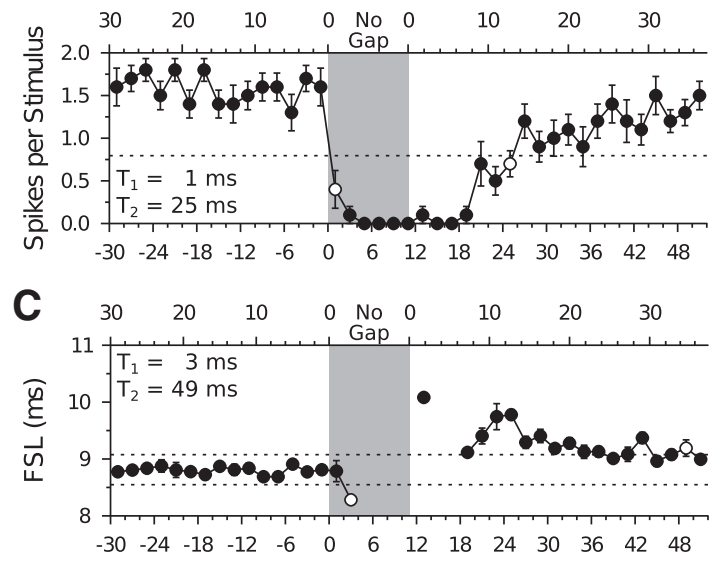

$\begin{array}{llllllllll}D & 30 & 20 & 10 & 0 & \text { No } & 0 & 10 & 20 & 30\end{array}$

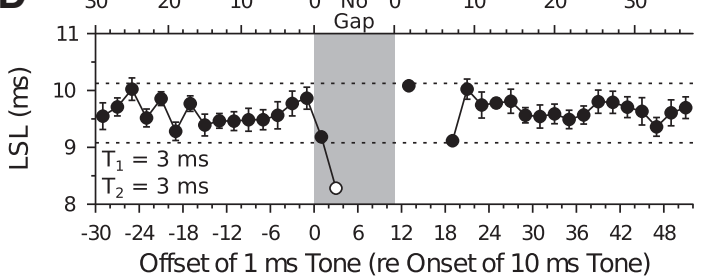

Dichotic

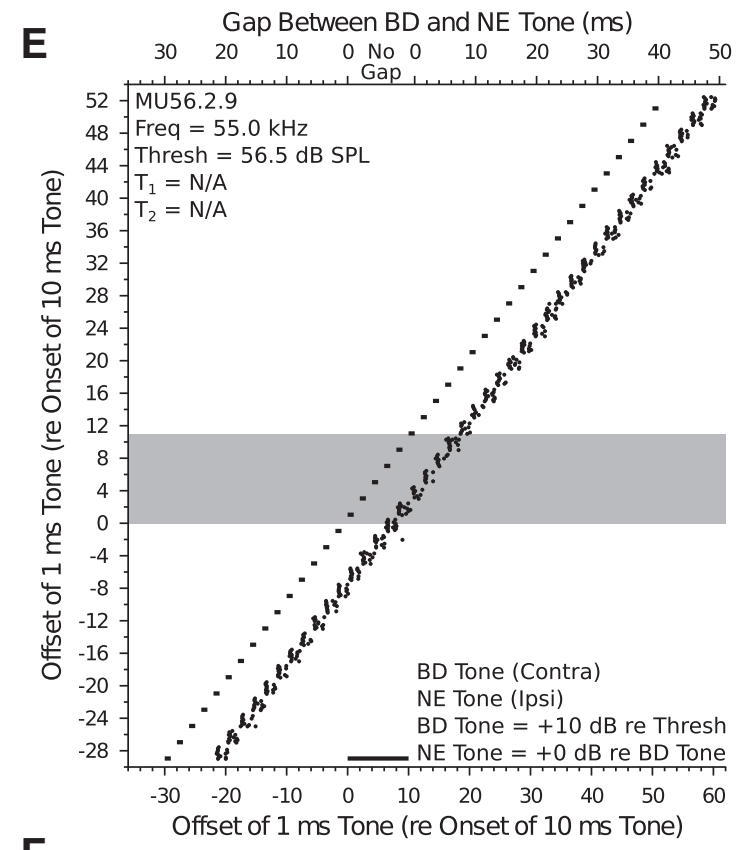

$\mathbf{F}$

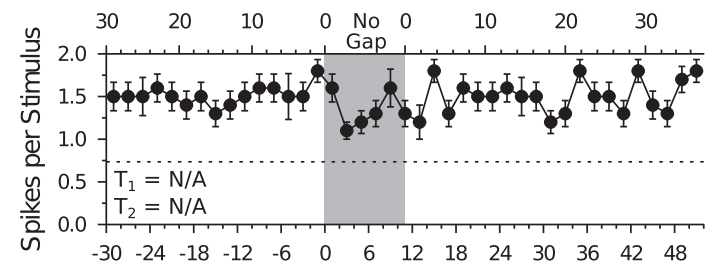

$\begin{array}{llllllllll}\mathbf{G} & 30 & 20 & 10 & 0 & \text { No } & 0 & 10 & 20 & 30\end{array}$

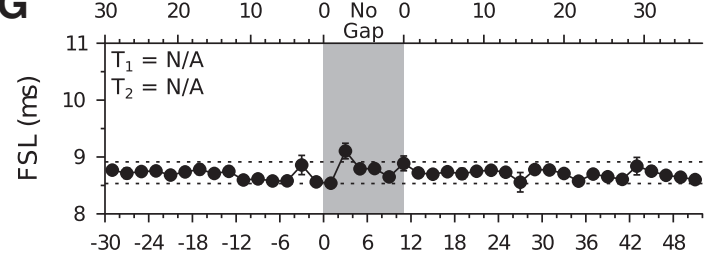

$\begin{array}{llllllllll}H & 30 & 20 & 10 & 0 & \text { No } & 0 & 10 & 20 & 30\end{array}$

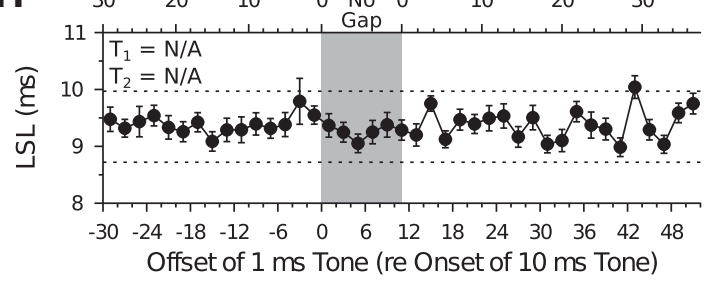

Figure 2. Example 1, Comparing monotic and dichotic paired tone stimulation. Dot raster display illustrating spike suppression in a short-pass DTN in response to monotic (left) but not dichotic (right) paired tone stimulation. $A$, When both tones were presented to the contralateral ear, spike suppression occurred when the $1 \mathrm{~ms} B D$ tone and the $10 \mathrm{~ms} N E$ tone were sufficiently close in time. $B$, Mean \pm SE spikes per stimulus as a function of the ISI between the BD and NE tones. The shortest ISI in which the spike count was $\leq 50 \%$ of baseline was $T_{1}=1 \mathrm{~ms}$. The longest ISI, starting from $T_{1}$, in which the spike count was $\leq 50 \%$ of baseline was $T_{2}=25 \mathrm{~ms}$. C, Mean \pm SEFSL as a function of the ISI between the BD and NE tones. The shortest ISI in which the FSL deviated by $>1$ SD from baseline was $T_{1}=3 \mathrm{~ms}$, and the longest ISI in which the FSL deviated by $>1$ SD from baseline was $T_{2}=49 \mathrm{~ms}$. $D$, Mean \pm SE LSL as a function of the ISI between the BD and NE tones. The shortest and longest ISIs in which the LSL deviated by $>1 \mathrm{SD}$ from baseline was $T_{1}=T_{2}=3 \mathrm{~ms}$. In the monotic condition, the earliest $T_{1}$ time was $1 \mathrm{~ms}$, determined with spike counts, and the longest $T_{2}$ time was $49 \mathrm{~ms}$, determined with FSL. In the monotic condition, the latency of inhibition lagged behind the excitatory FSL by $0.79 \mathrm{~ms}$, and the inhibition persisted $37.21 \mathrm{~ms}$ longer than the NE tone. $E$, Dot raster display illustrating the responses of the same DTN to dichotic paired tone stimulation (BD tone to contralateral ear; NE tone to ipsilateral ear). There was no significant change in the spike count $(\boldsymbol{F})$, FSL $(\boldsymbol{G})$, or LSL $(\boldsymbol{H})$ of the cell. This example shows no evidence of ipsilaterally evoked inhibition; therefore, the inhibition that created the duration-selective response of the neuron was purely monaural and evoked by stimulation of the contralateral ear. Contra, Contralateral; Freq, frequency; Ipsi, ipsilateral; Thresh, threshold.

excitation and inhibition was within the measurement resolution ( $2 \mathrm{~ms}$ ) of the stimulus paradigm. The cell had strong persistent inhibition, revealed by changes in both its spike count (Fig. 2B) and FSL (Fig. 2C), because the duration of spike suppression lasted $37.21 \mathrm{~ms}$ longer than the $10 \mathrm{~ms} \mathrm{NE}$ tone.
In the dichotic condition, spike suppression was no longer observed when the $\mathrm{BD}$ tone was presented to the contralateral ear and the NE tone was presented to the ipsilateral ear (Fig. 2E). At all ISIs, the spike count remained $\geq 50 \%$ of baseline (Fig. $2 F$ ), and neither the FSL nor the LSL deviated by $>1$ SD from baseline over two consecutive ISIs (Fig. 2G,H). 


\section{Monotic}

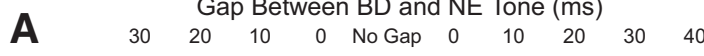

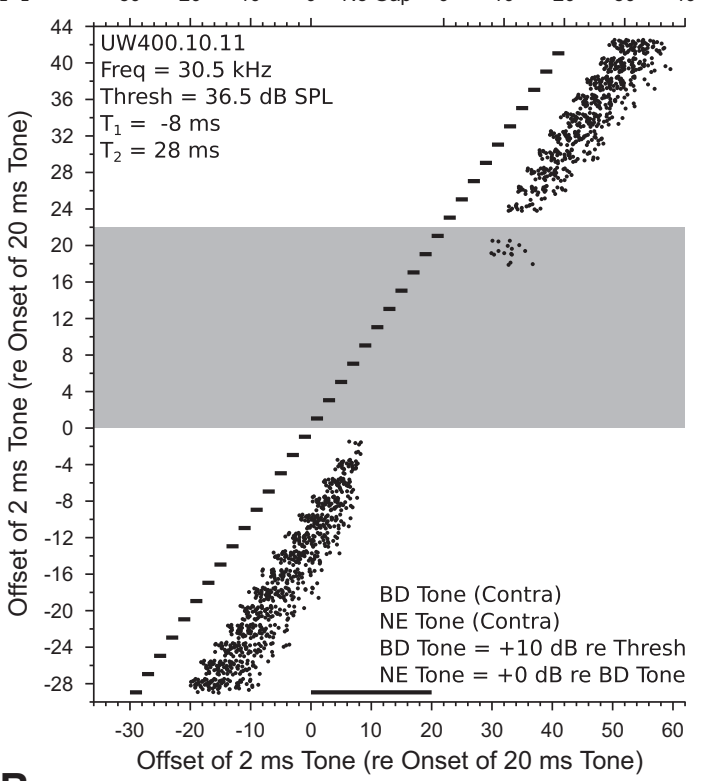

B

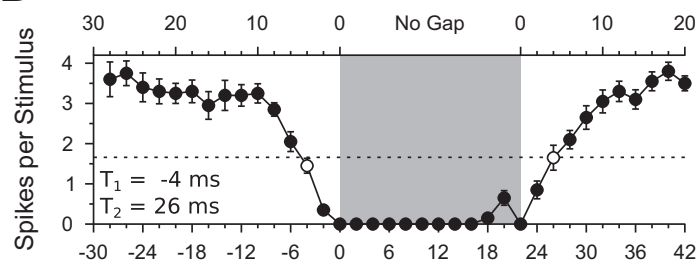

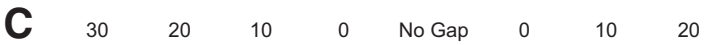

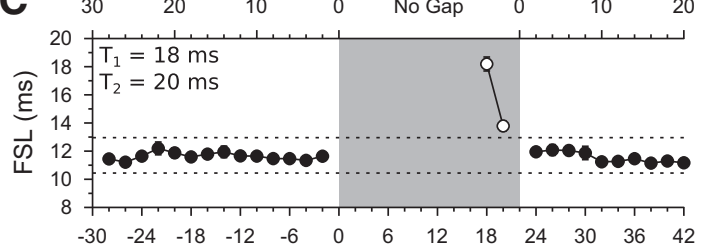

D

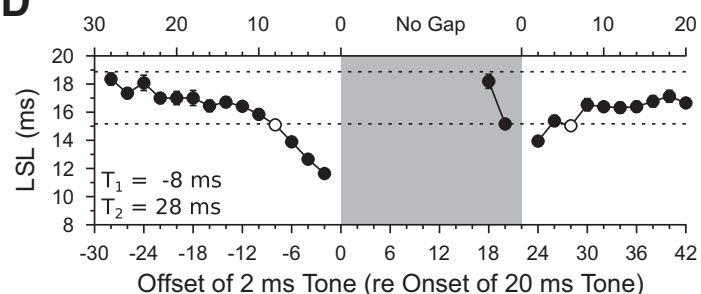

Dichotic

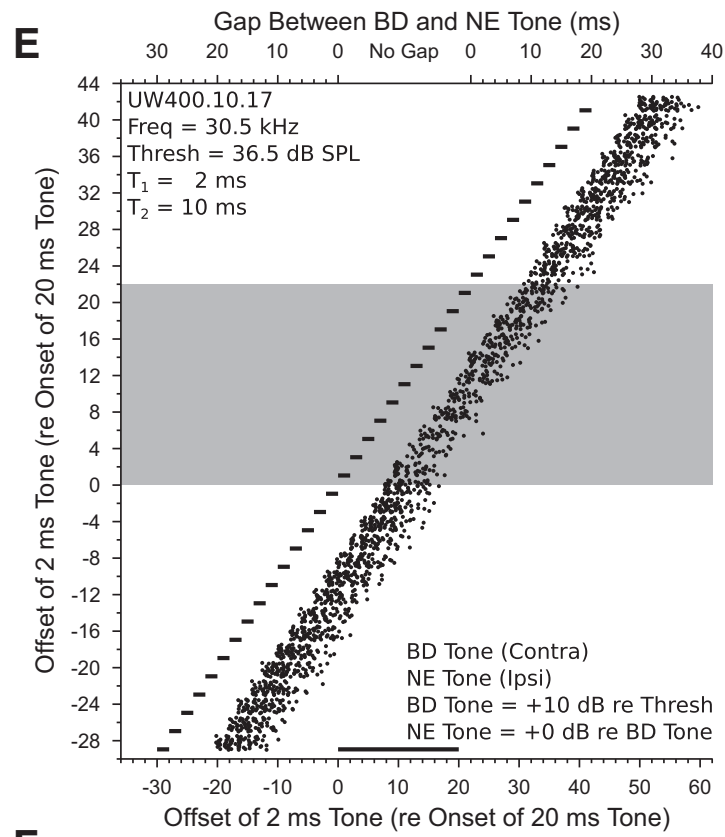

$\mathbf{F}$

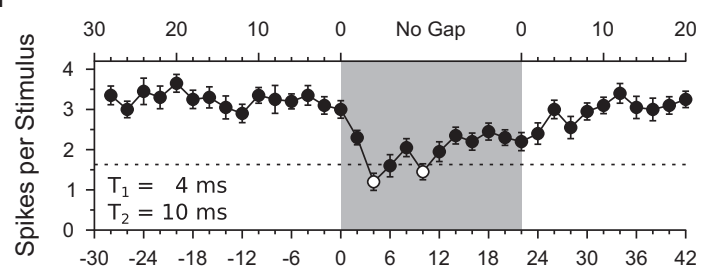

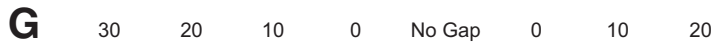

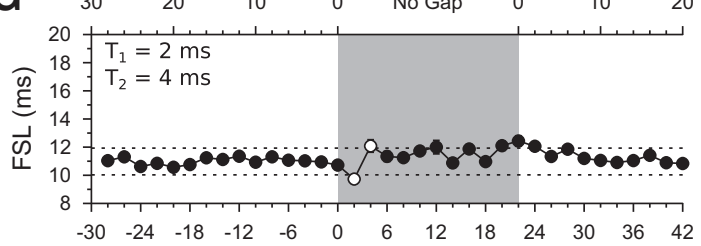

H

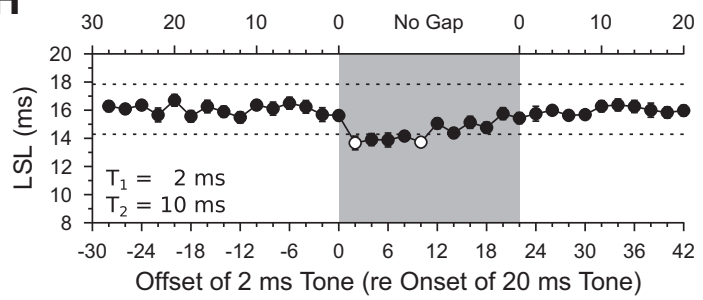

Figure 3. Example 2, Comparing monotic and dichotic paired tone stimulation. Dot raster display illustrating spike suppression in a bandpass DTN in response to monotic (left) and dichotic (right) paired tone stimulation. $\boldsymbol{A}$, When both tones were presented to the contralateral ear, spike suppression occurred when the $2 \mathrm{~ms} B D$ tone and the $20 \mathrm{~ms} N$ E tone were sufficiently close in time. $\boldsymbol{B}$, Mean \pm SE spikes per stimulus as a function of the ISI between the BD and NE tones. The first ISI in which the spike count was $\leq 50 \%$ of baseline was $T_{1}=-4 \mathrm{~ms}$. The longest ISI, starting from $T_{1}$, in which the spike count was $\leq 50 \%$ of baseline was $T_{2}=26 \mathrm{~ms}$. C, Mean \pm SEFSL as a function of the ISI between the BD and NE tones. The shortest ISI in which the FSL deviated by $>1 S D$ from baseline was $T_{1}=18 \mathrm{~ms}$, and the longest ISI in which the FSL deviated by $>1 S D$ from baseline was $T_{2}=20 \mathrm{~ms}$. D, Mean \pm SE LSL as a function of the ISI between the BD and NE tones. The shortest and longest ISIs in which the LSL deviated by $>1 \mathrm{SD}$ from baseline was $T_{1}=-8 \mathrm{~ms}$ and $T_{2}=28 \mathrm{~ms}$, respectively. In the monotic condition, the earliest $T_{1}$ time was $-8 \mathrm{~ms}$ and the longest $T_{2}$ time was $28 \mathrm{~ms}$, and both were determined using a change in LSL. In the monotic condition, the latency of inhibition preceded the excitatory FSL by $4.68 \mathrm{~ms}$, and this inhibition persisted $10.68 \mathrm{~ms}$ longer than the NE tone. $E$, Dot raster display illustrating responses of the same DTN to dichotic paired tone stimulation (BD tone to contralateral ear; NE tone to ipsilateral ear). The inhibition evoked by the NE tone caused a brief change in the spike count $(\boldsymbol{F}), \mathrm{FSL}(\boldsymbol{G})$, and $\mathrm{LSL}(\boldsymbol{H})$ of the cell. In the dichotic condition, the latency of inhibition lagged the excitatory FSL by $5.09 \mathrm{~ms}$, and the duration of the inhibition was $2.91 \mathrm{~ms}$. This example shows that the inhibition evoked by the NE tone in the dichotic condition was weaker, shorter in duration, and occurred at a longer latency than the inhibition evoked in the monotic condition. Contra, Contralateral; Freq, frequency; Ipsi, ipsilateral; Thresh, threshold.

Figure 3 shows an example of responses evoked from a bandpass DTN tested with monotic and dichotic paired tone stimulation using equal-amplitude $\mathrm{BD}$ and $\mathrm{NE}$ tones. In contrast to the example shown in Figure 2, spike suppression was observed in this cell for both the monotic and dichotic conditions. In the monotic condition, when the $2 \mathrm{~ms} \mathrm{BD}$ tone and the $20 \mathrm{~ms} \mathrm{NE}$ tone were presented to the contralateral ear (Fig. $3 A$ ), again there was nearly complete response suppression as the offset of the $\mathrm{BD}$ 
tone approached the onset of the NE tone (Fig. $3 B$ ) but with no change in FSL when spikes were evoked; however, a clear increase in FSL was observed for spikes that were evoked near the end of the stimulus overlap (Fig. 3C). Note also the change in LSL as the $\mathrm{BD}$ tone approached the NE tone (Fig. 3D). This decrease was caused by the inhibition evoked from the stationary NE tone suppressing the last spikes in the responses evoked by the $\mathrm{BD}$ tone (Fig. 3A). The final values for $T_{1}$ and $T_{2}$ were -8 and $28 \mathrm{~ms}$, respectively, and were derived from LSL changes. The effective duration of spike suppression was calculated to be $30.68 \mathrm{~ms}$. This neuron had leading inhibition because $L_{\text {first }}=11.70 \mathrm{~ms}$ and $T_{\text {start }}=7.02 \mathrm{~ms}$, hence the onset of inhibition preceded the FSL by $4.68 \mathrm{~ms}$. The cell also had persistent inhibition because the effective duration of spike suppression lasted $10.68 \mathrm{~ms}$ longer than the $20 \mathrm{~ms}$ NE tone.

In the dichotic condition, response suppression was again observed when the roving $\mathrm{BD}$ tone was presented to the contralateral ear and the stationary NE tone was presented to the ipsilateral ear; however, the inhibition evoked by the NE tone caused only a brief change in the spike count (Fig. 3F), FSL (Fig. 3G), and LSL of the cell (Fig. $3 G$ ). The final value for $T_{1}$ was $2 \mathrm{~ms}$ and was derived from spike latency changes; the final value for $T_{2}$ was $10 \mathrm{~ms}$ and was derived from a consensus between spike count and LSL changes. The effective duration of spike suppression was $2.91 \mathrm{~ms}$. In contrast to the monotic condition, the suppression observed in the dichotic condition was weaker, shorter in duration, and delayed until after the $\mathrm{BD}$ tone had completely overlapped the $\mathrm{NE}$ tone. The cell did not show leading inhibition in the dichotic condition because $L_{\text {first }}=10.98 \mathrm{~ms}$ and $T_{\text {start }}=16.07 \mathrm{~ms}$, hence the onset of the inhibition was delayed by $5.09 \mathrm{~ms}$ relative to the FSL. The cell did not have persistent inhibition because the effective duration of spike suppression was $17.09 \mathrm{~ms}$ shorter than the $20 \mathrm{~ms}$ NE tone. The change in the latency, strength, and duration of the response suppression in the dichotic condition suggests that the inhibition evoked through stimulation of the ipsilateral ear differed from the inhibition that was evoked through stimulation of the contralateral ear.

All 42 DTNs exhibited spike suppression in the monotic condition, but only 20 cells ( $47.6 \%$ ) showed spike suppression in the dichotic condition with equal-amplitude $\mathrm{BD}$ and NE tones. This difference was highly significant (Fisher's exact test, $p<0.0001$ ). The finding that less than half of the DTNs showed no evidence of inhibition recruited by stimulation of the ipsilateral ear supports the hypothesis that the inhibition and neural circuits responsible for creating the temporally selective responses of DTNs are monaural.

We measured the baseline FSL $\left(L_{\text {first }}\right)$ and latency of the inhibition evoked by the NE tone $\left(T_{\text {start }}\right)$ for each DTN tested with monotic and dichotic paired tone stimulation and calculated the latency difference $\left(L_{\text {first }}-T_{\text {start }}\right)$ to determine whether the inhibition preceded, was simultaneous with, or followed excitation. A positive difference indicates that inhibition led excitation; a negative difference indicates that inhibition lagged excitation (see above, Materials and Methods, Determining the time course of inhibition). The histograms in Figure 4 show the number of DTNs with leading and lagging inhibition in the monotic and dichotic conditions when the BD and NE tones were equal in amplitude (but not in energy). In the monotic condition (Fig. $4 A$ ), leading inhibition was observed in 34 of 42 cells (80.95\%); however, in the dichotic condition (Fig. 4B), only 4 of 20 cells (20\%) showed leading inhibition. The proportion of DTNs with leading inhibition in the monotic and dichotic conditions was significantly different (Fisher's exact test, $p<0.0001$ ). In the monotic condition, the mean \pm SD difference of $L_{\text {first }}-T_{\text {start }}$ was

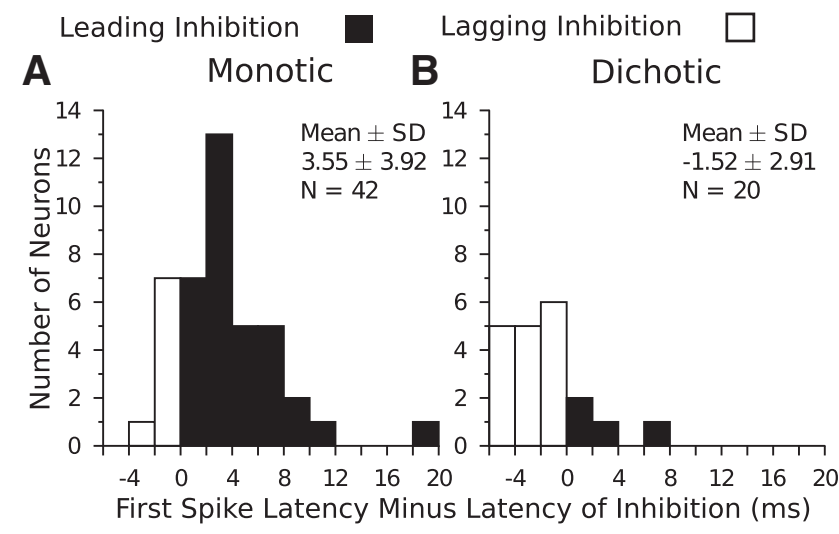

Figure 4. Histograms of the difference between the excitatory FSL and the latency of the inhibition evoked by the NE tone for DTNs tested with monotic and dichotic paired tone stimulation. Cells with a positive latency difference are illustrated with filled bars and represent neurons in which the onset of inhibition preceded the baseline FSL (i.e., leading inhibition). Cells with a negative latency difference are illustrated with open bars and represent neurons in which the onset of inhibition lagged the baseline FSL (i.e., lagging inhibition). $\boldsymbol{A}$, The majority of DTNs tested in the monotic condition had leading inhibition. $\boldsymbol{B}$, A majority of DTNs tested in the dichotic condition had lagging inhibition. The distributions of $L_{\text {first }}-T_{\text {start }}$ in the monotic and dichotic conditions were significantly different (Mann-Whitney $U=742.00, p \ll 0.001$ ).

$3.55 \pm 3.92 \mathrm{~ms}$, whereas in the dichotic condition, it was $-1.52 \pm$ $2.91 \mathrm{~ms}$; the difference between the two distributions was statistically significant (Fig. 4). These data reveal that the inhibitory inputs recruited by stimulation of the contralateral ear during monotic stimulation have a shorter latency than the inhibitory inputs recruited by the ipsilateral ear during dichotic stimulation.

The histograms in Figure 5 illustrate the time course of the inhibition evoked during monotic and dichotic paired tone stimulation relative to the duration of the NE tone that evoked the inhibition. The plots show the effective duration of inhibition minus the duration of the NE tone (i.e., $T_{\text {end }}-T_{\text {start }}-D_{\mathrm{NE}}$ ). A positive difference indicates persistent inhibition; a negative difference indicates that the inhibition evoked by the NE tone was shorter in duration than the NE tone itself (see above, Materials and Methods, Determining the time course of inhibition). We observed persistent inhibition in 42 of 42 DTNs (100\%) tested in the monotic condition with equal-amplitude $\mathrm{BD}$ and $\mathrm{NE}$ tones. In some cells, the inhibition persisted $>50 \mathrm{~ms}$ after the offset of the NE tone (Fig. 5A). In the dichotic condition, only 20 of 42 neurons $(47.6 \%)$ were inhibited by the NE tone, and the total duration of this inhibition was usually shorter than the duration of the NE tone that evoked it (Fig. 5B). Indeed, persistent inhibition was observed in only 5 of 20 DTNs $(25 \%)$ tested in the dichotic condition. The difference in the proportion of cells with persistent inhibition in the monotic and dichotic conditions was highly significant (Fisher's exact test, $p<0.0001$ ). In the monotic condition, the mean $\pm \mathrm{SD}$ difference of $T_{\text {end }}-T_{\text {start }}-D_{\mathrm{NE}}$ was $19.70 \pm 13.22 \mathrm{~ms}$, whereas in the dichotic condition, it was $-2.32 \pm 17.25 \mathrm{~ms}$; the difference between the two distributions was statistically significant (Fig. 5). These data reveal that the inhibition recruited by the contralateral ear during monotic paired tone stimulation persistent longer than the inhibition recruited by the ipsilateral ear during dichotic paired tone stimulation.

\section{Comparing monotic and dichotic inhibitory responses}

To highlight differences in the latency and time course of the inhibition evoked by the NE tone during monotic and dichotic paired tone stimulation, we conducted a detailed paired analysis 


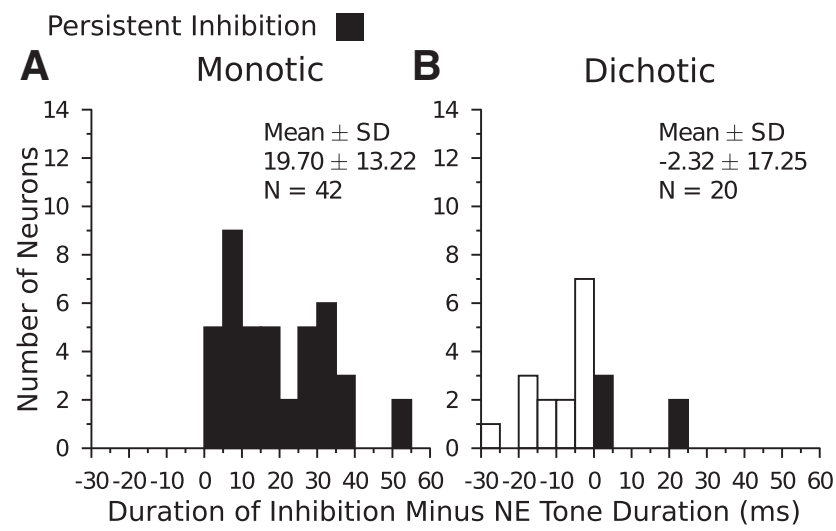

Figure 5. Histograms of the difference between the duration of the inhibition evoked by the NE tone and the duration of the NE tone for DTNs tested with monotic and dichotic paired tone stimulation. Cells with a positive latency difference are illustrated with filled bars and represent neurons in which the duration of inhibition was longer than the duration of the NE tone that evoked the inhibition (i.e., persistent inhibition). Cells with a negative latency difference are illustrated with open bars and represent neurons in which the duration of inhibition was shorter than the duration of the NE tone that evoked the inhibition. $A$, Every DTN tested in the monotic condition had persistent inhibition. $\boldsymbol{B}$, The majority of DTNs tested in the dichotic condition had durations of inhibition that were shorter than the duration of the NE tone presented to the ipsilateral ear. The distributions of $T_{\text {end }}-T_{\text {start }}-D_{\mathrm{NE}}$ in the monotic and dichotic conditions were significantly different (Mann-Whitney $U=787.00, p \ll 0.001$ ).

on the responses of those 20 DTNs with measurable inhibition in both conditions using equal-amplitude $\mathrm{BD}$ and NE tones. The latency of the inhibition $\left(T_{\text {start }}\right)$ evoked during monotic stimulation was significantly shorter than the latency of the inhibition evoked during dichotic stimulation in the same cells (Fig. 6A). Moreover, the effective duration of the inhibition $\left(T_{\text {end }}-T_{\text {start }}\right)$ evoked in the monotic condition was significantly longer than it was in the dichotic condition in the same cells (Fig. 6B). When we subtracted the latency of the inhibition from the baseline FSL, most DTNs showed leading inhibition in the monotic condition but had lagging inhibition in the dichotic condition (Fig. 6C). We also compared the effective duration of the inhibition relative to the duration of the NE tone that evoked the inhibition $\left(T_{\text {end }}-\right.$ $\left.T_{\text {start }}-D_{\mathrm{NE}}\right)$ and observed that all DTNs had persistent inhibition in the monotic condition, whereas few had persistent inhibition in the dichotic condition (Fig. 6D). Importantly, these results did not depend on the criteria used to measure the inhibition because all differences remained significant when the suppression was quantified using only changes in spike counts or spike latencies (data not shown). Altogether, these data suggest that a subpopulation of DTNs can receive two distinct types of inhibitory inputs: (1) one that is fast and long-lasting, evoked by stimulation of the contralateral ear, and responsible for creating duration-selective responses; and (2) another that is slower and shorter-lasting, evoked by stimulation of the ipsilateral ear, and participates in the binaural response of the cell.

\section{Relation of leading/lagging inhibition to $\mathrm{BD}, \mathrm{FSL}$, and duration filter characteristic}

Conceptual and computational models of DTNs predict that the BD and range of duration selectivity will depend, in part, on the amount of time by which inhibition leads excitation (Casseday et al., 1994, 2000; Aubie et al., 2009, 2012). A previous study reported a positive correlation between the amount of leading inhibition and the neuronal $\mathrm{BD}$ in a sample of DTNs tested with monotic paired tone stimulation (Faure et al., 2003). That study also reported a positive correlation between leading inhibition and FSL.
We measured the latency of inhibition evoked by the NE tone during monotic and dichotic paired tone stimulation and subtracted this from the baseline FSL of the cell in each condition to evaluate the relationship of leading/lagging inhibition to the $\mathrm{BD}$, FSL and duration filter characteristic (Fig. 7). In the monotic condition, there was a positive correlation between the BD and the time by which contralateral inhibition led excitation (Fig. $7 A$ ). Leading inhibition was also significantly larger in bandpass DTNs than short-pass DTNs (bandpass $=4.60 \pm 0.94 \mathrm{~ms}$; shortpass $=1.60 \pm 0.89 \mathrm{~ms}$; Mann-Whitney $U=81.00, p \ll 0.001)$. These findings replicate the results of Faure et al. (2003). In the dichotic condition, there was no relation between the BD and the amount of leading/lagging inhibition (Fig. $7 B$ ). Moreover, there was no difference in the amount of leading/lagging ipsilateral inhibition between bandpass and short-pass DTNs (bandpass = $-1.92 \pm 1.08 \mathrm{~ms}$; short-pass $=1.60 \pm 0.89 \mathrm{~ms} ; t_{(18)}=0.443$, $p=0.663)$.

In the monotic condition, there was a positive correlation between the amount of leading/lagging inhibition and the baseline FSL; DTNs with short FSLs had shorter durations of leading/ lagging inhibition than cells with longer FSLs (Fig. 7C). This finding was also reported by Faure et al. (2003); however, in the present study, the difference in FSL between bandpass and shortpass DTNs was not significant (bandpass $=14.39 \pm 1.05 \mathrm{~ms}$; short-pass $=13.45 \pm 1.15 \mathrm{~ms}$; Mann-Whitney $U=174.00$, $p=0.247)$. In the dichotic condition, there was no correlation between leading/lagging inhibition and the baseline FSL (Fig. $7 D$ ). There was also no difference in FSL between bandpass and short-pass DTNs (bandpass $=13.74 \pm 1.05 \mathrm{~ms}$; short-pass $=$ $13.33 \pm 1.39 \mathrm{~ms}$; Mann-Whitney $U=172.00, p=0.227)$. Together, these data support the following hypotheses. First, monaural inhibition from the contralateral ear is responsible for shaping the BD, FSL, and duration filter characteristic of DTNs. Second, inhibition from the ipsilateral ear, when present, is not a major determinant of $\mathrm{BD}, \mathrm{FSL}$, or the duration filter characteristic of DTNs.

\section{Effect of increasing NE tone amplitude in the dichotic condition}

Finally, we explored the effect of increasing the amplitude of the NE tone during dichotic paired tone stimulation. In this experiment, the amplitude of the $\mathrm{BD}$ tone in the contralateral ear was fixed, typically at +10 or $+20 \mathrm{~dB}$ above threshold, while the amplitude of the NE tone in the ipsilateral ear was varied from $+0,+10$, or $+20 \mathrm{~dB}$ relative to the $\mathrm{BD}$ tone (Fig. $8 \mathrm{~A}$ ). We limited the dichotic amplitude difference to $+20 \mathrm{~dB}$ to reduce the likelihood of acoustic crosstalk from the ipsilateral ear suppressing spikes evoked via stimulation of the contralateral ear (Ehrlich et al., 1997).

Figure $8 B$ shows an example of responses evoked from a shortpass DTN as the amplitude of the NE tone was increased in the dichotic condition. This cell did not show ipsilaterally evoked inhibition until the amplitude of the NE tone was $20 \mathrm{~dB}$ louder than the $\mathrm{BD}$ tone. The duration of response suppression was measured in this cell by a change in spike count, but similar suppressive effects were observed when we examined FSL and LSL changes (latency data not shown). Figure $8 C$ shows an example of responses evoked from a bandpass DTN as the amplitude of the NE tone was increased during dichotic stimulation. This cell did not show ipsilaterally evoked inhibition at any amplitude of the NE tone regardless of the criterion used to measure response suppression (latency data not shown).

Of 21 DTNs tested, only four (19.0\%) exhibited spike suppression in the dichotic condition when the $\mathrm{BD}$ and NE tones 
A
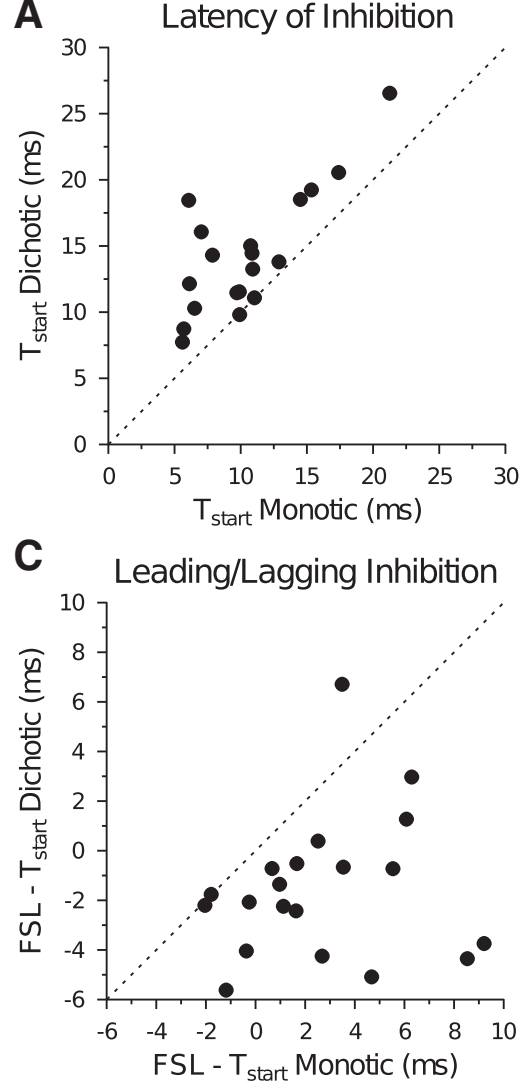

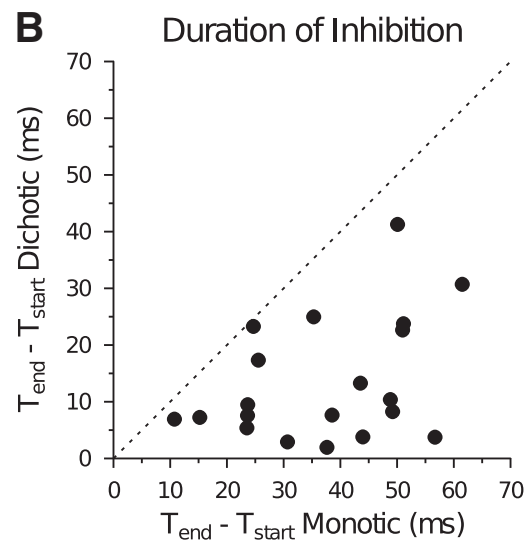

D

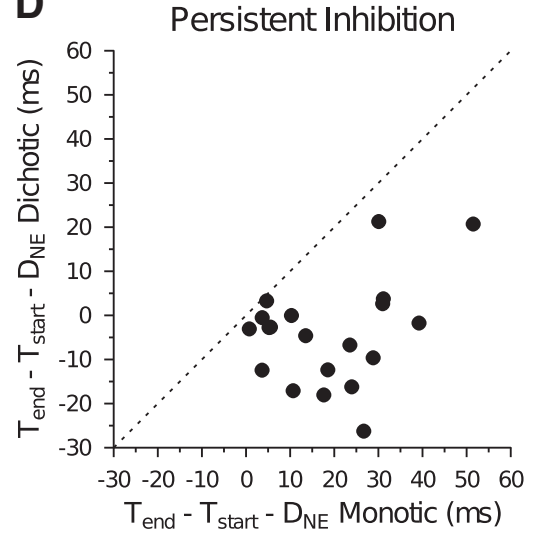

Figure 6. Comparing the latency and time course of the inhibition evoked in DTNs during monotic and dichotic paired tone stimulation. Only cells that exhibited measurable inhibition in both conditions were included in this paired analysis $(n=20)$. In each panel, the inhibition recruited monaurally is plotted on the $x$-axis, the inhibition recruited binaurally is plotted on the $y$-axis, and the dotted line is the unity line $(y=x)$ indicating that monaural inhibition = binaural inhibition. $\boldsymbol{A}$, The latency of the inhibition $\left(T_{\text {start }}\right)$ recruited by the NE tone was significantly longer in the dichotic condition (Wilcoxon's signed-rank test, $Z=$ $-3.845, p \ll 0.001)$, as evidenced by the majority of points falling above the unity line. $\boldsymbol{B}$, The duration of the inhibition $\left(T_{\text {end }}-\right.$ $\left.T_{\text {start }}\right)$ evoked by the NE tone was significantly longer in the monotic condition $\left(t_{(19)}=4.605, p \ll 0.001\right)$, as evidenced by the majority of points falling below the unity line. $C$, The difference between the FSL and latency of inhibition $\left(L_{\text {first }}-T_{\text {start }}\right)$ was usually positive in the monotic condition indicating leading contralateral inhibition but was usually negative in the dichotic condition indicating lagging ipsilateral inhibition (Wilcoxon's signed-rank test, $Z=-3.920, p \ll 0.001$ ). $D$, The difference between the effective duration of inhibition and the NE tone duration $\left(T_{\text {end }}-T_{\text {start }}-D_{\mathrm{NE}}\right)$ was always positive in the monotic condition indicating persistent contralateral inhibition but was usually negative in the dichotic condition indicating shorter lasting ipsilateral inhibition $\left(t_{(19)}=6.934, p \ll 0.001\right)$.

were equal in amplitude. When the amplitude of the NE tone was increased to $+10 \mathrm{~dB}$ (relative to BD tone), 9 of 21 cells $(42.8 \%$ ) showed spike suppression. When the amplitude of the NE tone was increased to $+20 \mathrm{~dB}$ (relative to BD tone), 16 of 21 neurons (76.2\%) showed suppression. We also measured the effective duration of the inhibition at each NE tone amplitude; cells that did not meet the criteria for response suppression were assigned a value of 0 ms. A nonparametric equivalent to a repeated-measures ANOVA (Friedman's test) revealed that there was a significant increase in the effective duration of inhibition as the amplitude of the NE tone was increased in the ipsilateral ear (Fig. 8D).

\section{Discussion}

\section{Inhibitory inputs that create DTNs are monaural}

A number of neural circuit models, backed by electrophysiological studies, have proposed biological mechanisms to explain the formation of duration-selective responses. Although there are variations to these models, most rely on the interaction of excitatory and inhibitory synaptic inputs (Casseday et al., 1994, 2000; Covey et al., 1996; Fuzessery and Hall, 1999; Faure et al., 2003;
Aubie et al., 2009, 2012; Sayegh et al., 2012). One key feature of the models is that DTNs receive a sustained inhibitory input that lasts as long as, or longer than, the duration of the stimulus evoking the inhibition. Combined with limited evidence from whole-cell patch-clamp and single-unit recordings (Casseday et al., 1994, 2000; Covey et al., 1996; Ehrlich et al., 1997; Faure et al., 2003; Leary et al., 2008), the models suggest that DTNs receive inhibitory inputs that precede their excitatory inputs.

Extracellular electrophysiology typically only allows researchers to observe the expression and/or suppression of action potentials. Using methods first described by Faure et al. (2003) and Covey and Faure (2005), we used paired tone stimulation, combined with single-unit recordings, to indirectly measure the latency and duration of the inhibition acting on DTNs. This technique works for DTNs because the paradigm uses an excitatory BD tone that reliably evokes spiking as a probe stimulus and a NE tone that reliably suppresses spikes evoked by the $\mathrm{BD}$ tone (Fig. 1). Although we used the NE tone as an inhibitory stimulus, it is important to note that the $\mathrm{BD}$ and $\mathrm{NE}$ tones activated both excitatory and inhibitory synaptic inputs (Casseday et al., 1994, 2000; Covey et al., 1996; Fuzessery and Hall, 1999; Faure et al., 2003); however, the net effect of the NE tone was inhibitory and the net effect of the BD tone was excitatory (Faure et al., 2003, their Fig. $2 B$ ). Therefore, the influence of the NE tone on the spike counts and latencies evoked by BD tone resulted from the combined effects of excitation and inhibition.

In this study, we found that all DTNs exhibited spike suppression during monotic paired tone stimulation when equal-amplitude BD and NE tones were presented monaurally to the contralateral ear, whereas half of the DTNs showed no spike suppression during dichotic paired tone stimulation when the $\mathrm{BD}$ tone was presented to the contralateral ear and an NE tone of equal amplitude was presented to the ipsilateral ear (Figs. 2-5). The fact that many DTNs were not inhibited by stimulation of the ipsilateral ear clearly demonstrates that monaural circuits provide the inhibition needed to create duration selectivity. In the monotic condition, the latency of the inhibition evoked by the NE tone was shorter than the FSL of a cell, a finding that is consistent with previous studies showing that the inhibitory inputs to DTNs precede their excitatory inputs. Only half of the DTNs showed spike suppression in the dichotic condition, and of those, most had latencies of inhibition evoked by the NE tone that were longer than the excitatory FSL of the cell, revealing that ipsilateral inhibition usually lagged contralateral excitation (Fig. 6)

In the monotic condition, all DTNs showed sustained inhibition that lasted as long as, or longer than, the duration of the NE 
tone, a finding also reported previously (Faure et al., 2003), whereas in the dichotic condition, the duration of inhibition was usually shorter than the duration of the NE tone that evoked the inhibition (Figs. 5, 6). These results indicate that the neural circuits and mechanisms that create duration-selective cells in the auditory midbrain are primarily monaural.

When ipsilateral inhibition was evoked, it was weaker, slower, and shorter in duration than the contralaterally evoked inhibition to the same cell (Fig. 6) but grew with increasing amplitude of the NE tone (Fig. 8). Together, these results demonstrate that the synaptic inhibition that is responsible for creating DTNs in mammals is recruited through monaural, contralateral auditory pathways and is independent of the ipsilateral inhibition that shapes the interaural level difference (ILD) tuning profile of many IC neurons.

\section{Effect of increasing NE tone amplitude in the dichotic condition}

The IC receives converging bilateral inputs from a number of monaural and binaural auditory nuclei (Adams, 1979; Zook and Casseday, 1982), so it is natural to expect that the neural inputs responsive to sound stimulation at each ear play a role in shaping the response characteristics of IC neurons. In a previous report on binaural interactions in the IC of the big brown bat, $\sim 61 \%$ of cells were classified as EI because they received an excitatory (E) input when the contralateral ear was stimulated and an inhibitory (I) input when the ipsilateral ear was stimulated, and $32 \%$ of cells were classified as EO (monaural) because ipsilateral stimulation had no effect (O) on contralaterally evoked responses ( $\mathrm{Lu}$ and Jen, 2003). In the IC of the cat, the proportion of EI cells ranges from 26 to $41 \%$, depending on stimulus frequency, and the proportion of EO cells varies from 17 to 49\% (Semple and Aitkin, 1979; Irvine and Gago, 1990).

In our study, $52 \%$ of DTNs showed no evidence of receiving an ipsilaterally evoked inhibition when they were tested with dichotic paired tone stimulation using equal-amplitude BD and NE tones. In some cells, we were able to recruit binaural inhibition by increasing the amplitude of the ipsilateral NE tone relative to the contralateral BD tone (Fig. 8). Increasing the amplitude of the NE tone up to $+20 \mathrm{~dB}$ (relative to BD tone) induced spike suppression in 12 of 17 neurons that were not suppressed previously when the amplitude of the ipsilateral NE tone was equal to the amplitude of the contralateral BD tone. One possible explanation is that increasing the amplitude of the ipsilateral NE tone induced spike suppression via inadvertent stimulation of the contralateral ear through acoustic crosstalk; however, another study using identical loudspeakers reported $>30 \mathrm{~dB}$ of attenuation between the ears (Ehrlich et al., 1997), which is well above the + $20 \mathrm{~dB}$ ILD that we used with our dichotic stimuli. Crosstalk could have evoked an additional inhibitory response and increased spike suppression in the binaural condition when the NE tone was presented at a high amplitude relative to the BD tone, particularly
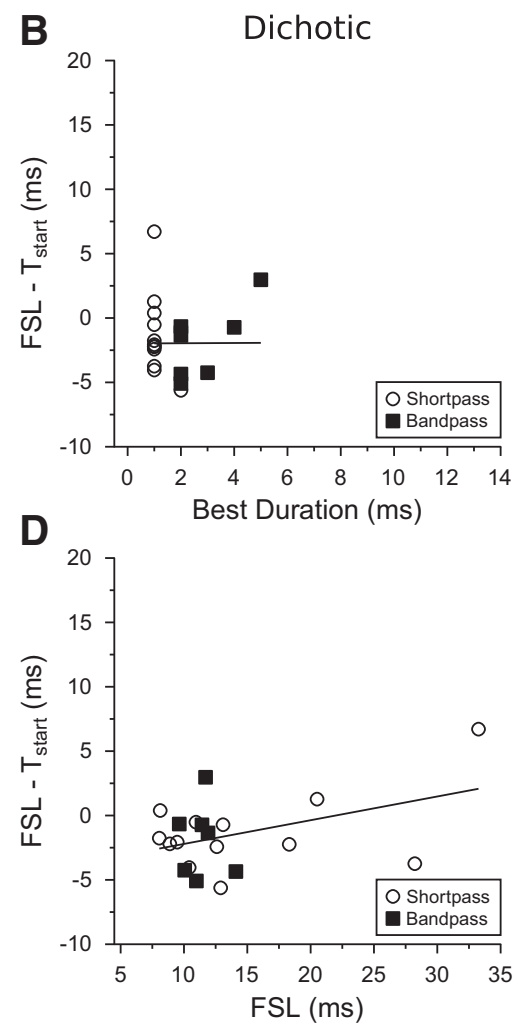

Monotic

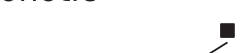

uration (ms)

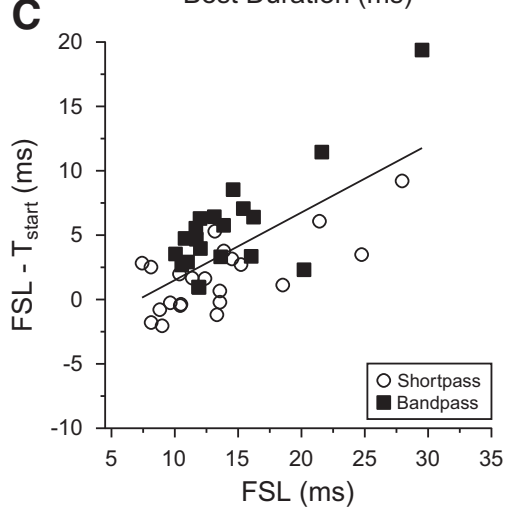

Figure 7. Relationship of leading/lagging inhibition to BD, FSL, and duration filter characteristic in DTNs tested with monotic and dichotic paired tone stimulation. $\boldsymbol{A}$, The amount of time that inhibition led excitation in the monotic condition increased in 政 monotic condition increased in DTNs with longer baseline FSLs $\left(r^{2}=0.46 ; p \ll 0.001 ; n=42\right) ; \boldsymbol{D}$, however, there was no relationship between leading/lagging inhibition and baseline FSL for cells tested in the dichotic condition $\left(r^{2}=0.18 ; p=0.065 ; n=20\right)$.

for cells in which the threshold of inhibition was lower than that of excitation. The potential for acoustic crosstalk strengthens our hypothesis that the neural circuitry underlying the formation of DTNs is monaural. Moreover, the fact that some DTNs were never inhibited by stimulation of the ipsilateral ear clearly demonstrates that monaural auditory pathways provide all of the inhibition necessary to create duration-selective responses.

\section{Role of inhibition from the ipsilateral ear}

Our results clearly demonstrate that the inhibition responsible for creating the temporally selective responses of DTNs originates from monaural auditory pathways. This inhibition is recruited by stimulating the contralateral ear, is strong, fast, and onsetevoked, precedes excitation to the DTN, and is sustained for as long as, or longer than, the duration of the stimulus. When inhibition was recruited via stimulation of the ipsilateral ear, for the majority of DTNs, it was weaker and longer in latency than either the contralaterally evoked inhibition or excitation (Fig. 6). Our findings raise two important questions for future studies. Why do primarily monaural neurons exist at the level of the auditory midbrain, and what role do DTNs play in normal hearing?

Our results demonstrate that DTNs in the mammalian IC can receive at least two distinct types of inhibitory inputs. The first type is present in every cell, is evoked by stimulation of the contralateral ear, and is responsible for creating the temporally selective responses characteristic of DTNs. The second type of inhibition occurs in a subset of DTNs, is recruited by stimulation of the ipsilateral ear and interacts with the monaural inhibition, and is likely similar to the binaural inhibition evoked in other 
A

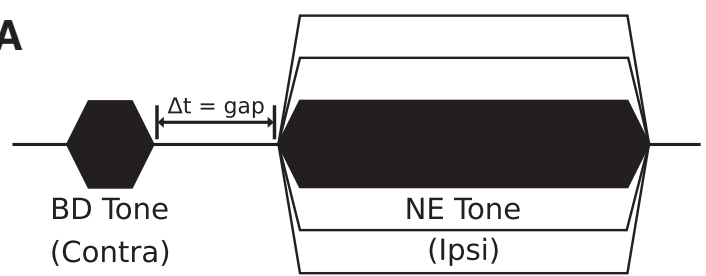

B

Gap Between BD and NE Tone (ms)

C
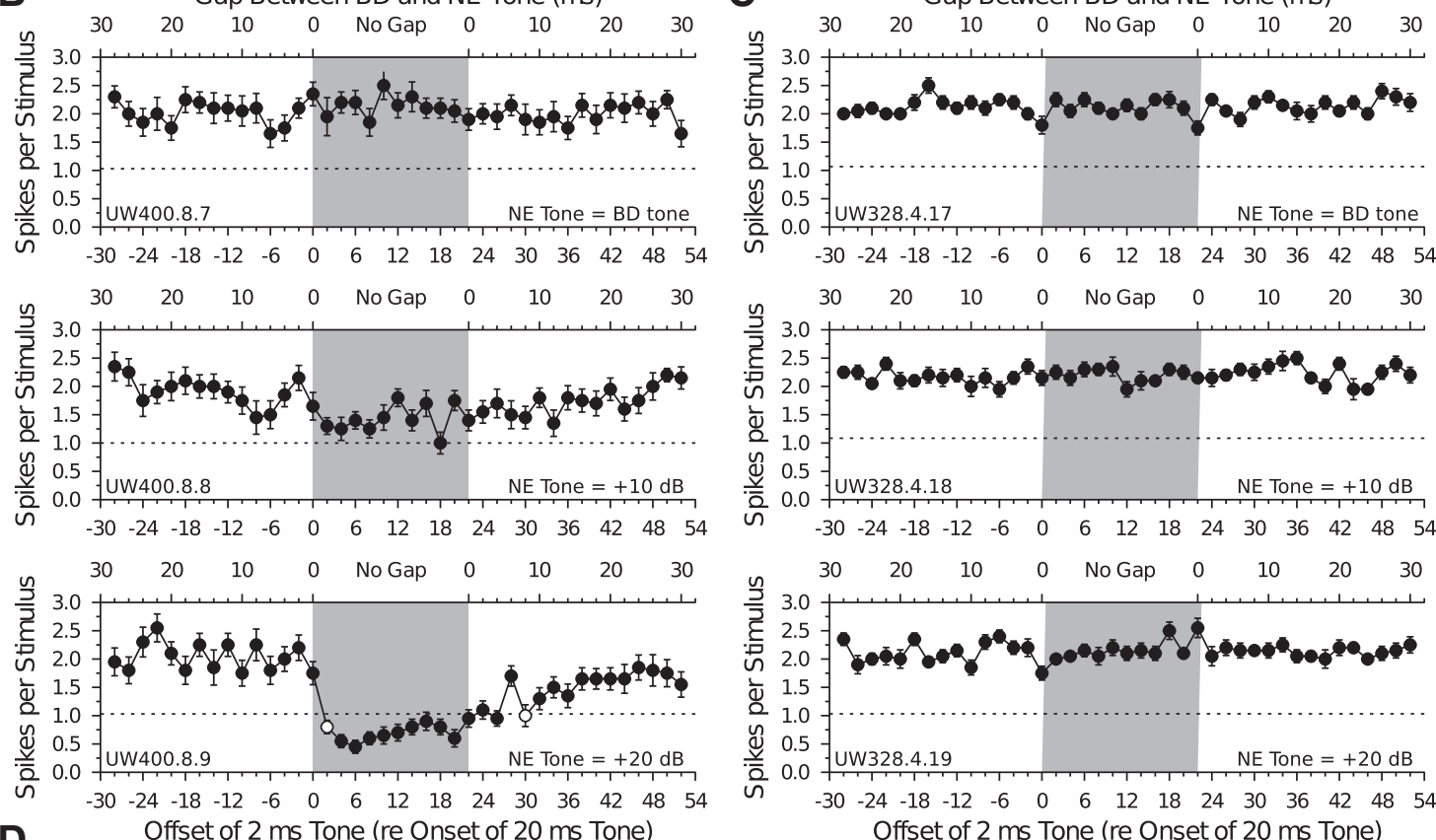

D

Offset of $2 \mathrm{~ms}$ Tone (re Onset of $20 \mathrm{~ms}$ Tone)

Offset of $2 \mathrm{~ms}$ Tone (re Onset of $20 \mathrm{~ms}$ Tone)

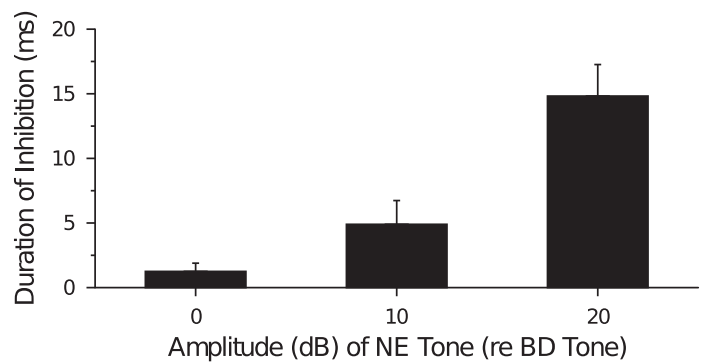

Figure 8. Effect of increasing the amplitude of the ipsilateral NE tone during dichotic paired tone stimulation. $A$, Schematic of the stimulus paradigm. A constant-amplitude BD tone was presented to the contralateral ear, and a variable-amplitude NE tone was presented to the ipsilateral ear (decibel increase not to scale). $\boldsymbol{B}$, Short-pass DTN with evidence of ipsilaterally evoked inhibition. Mean \pm SE spikes per stimulus as a function of the ISI between the BD and NE tones when the amplitude of the NE tone was $+0 \mathrm{~dB}$ (top), $+10 \mathrm{~dB}$ (middle), and $+20 \mathrm{~dB}$ (bottom) relative to the $B D$ tone. There was no effect of increasing the amplitude of the ipsilateral stimulus on $B D$ tone evoked responses until the NE tone was $+20 \mathrm{~dB}$ (relative to $B D$ tone). $D_{B D}=2 \mathrm{~ms} ; D_{\mathrm{NE}}=20 \mathrm{~ms}$; frequency $=32 \mathrm{kHz}$; threshold $=32.5 \mathrm{~dB} \mathrm{SPL} ; B D$ tone amplitude $=+10 \mathrm{~dB}$ relative to threshold; repetitions per stimulus $=20$. C, Bandpass DTN with no evidence of ipsilaterally evoked inhibition. Mean \pm SE spikes per stimulus as a function of the ISI between the BD and NE tones when the amplitude of the NE tone was $+0 \mathrm{~dB}$ (top), $+10 \mathrm{~dB}$ (middle), and $+20 \mathrm{~dB}$ (bottom) relative to the $B D$ tone. There was no effect of increasing the amplitude of the ipsilateral stimulus on $B D$ tone evoked responses. $D_{B D}=2 \mathrm{~ms} ; D_{\mathrm{NE}}=20 \mathrm{~ms}$; frequency $=23 \mathrm{kHz}$; threshold $=33 \mathrm{~dB} \mathrm{SPL} ; \mathrm{BD}$ tone amplitude $=+10 \mathrm{~dB}$ relative to threshold; repetitions per stimulus $=20$. D, Mean \pm SE duration of inhibition evoked by the ipsilateral NE tone when the amplitude of the NE tone was +0 , +10 , and $+20 \mathrm{~dB}$ (relative to $\mathrm{BD}$ tone). Increasing the amplitude of the NE tone caused a significant increase in the duration of the inhibition evoked through ipsilateral central auditory pathways [Friedman test, $\left.\chi^{2}(2, n=21)=24.947, p \ll 0.001\right]$. Contra, Contralateral; Ipsi, ipsilateral.

types of IC neurons. In the IC of bats, DTNs are known to receive two types of inhibitory neurotransmitters, GABA and glycine (Casseday et al., 2000). Although it is tempting to speculate that the two types of inhibitory inputs to DTNs reported in this study are using different neurotransmitters, for now this hypothesis awaits investigation.

\section{Monotic and dichotic temporal masking}

The paired tone stimulation paradigm we used on DTNs in the IC of the bat mirrors the design of auditory temporal masking experiments in human psychophysics (Faure et al., 2003). The change in spike count and latency that occurred when the $\mathrm{BD}$ tone preceded the NE tone is the neural equivalent of backward masking and was caused by the leading inhibition evoked by the NE tone suppressing spikes evoked by the BD tone. Similarly, the change in spiking that occurred when the BD and NE tones overlapped in time to form a single composite tone with an amplitude pedestal is the neural equivalent of simultaneous masking and was caused by the sustained inhibition evoked by the NE tone suppressing spikes evoked by the BD tone. The change in spiking that occurred when the $\mathrm{BD}$ tone followed the $\mathrm{NE}$ tone is the neural equivalent of forward masking and was caused by the 
persistent inhibition evoked by the NE tone altering responses evoked by the BD tone. Interestingly, psychophysical studies have shown that forward and backward masking last longer when humans are presented with monotic compared with dichotic stimuli (Elliott, 1962a,b; Deatherage and Evans, 1969). These behavioral findings mirror our single-cell neurophysiological results: DTNs tested with monotic paired tone stimulation had greater amounts of leading, sustained, and persistent inhibition than the same cells tested with dichotic paired tone stimulation (Fig. 6). These results suggest that leading, sustained, and persistent inhibition at the level of the midbrain are neural mechanisms that can help to explain temporal masking phenomena in human psychophysics.

\section{References}

Adams JC (1979) Ascending projections to the inferior colliculus. J Comp Neurol 183:519-538. CrossRef Medline

Aubie B, Becker S, Faure PA (2009) Computational models of millisecond level duration tuning in neural circuits. J Neurosci 29:9255-9270. CrossRef Medline

Aubie B, Sayegh R, Faure PA (2012) Duration tuning across vertebrates. J Neurosci 32:6373-6390. CrossRef Medline

Bohn KM, Schmidt-French B, Ma ST, Pollak GD (2008) Syllable acoustics, temporal patterns, and call composition vary with behavioral context in mexican free-tailed bats. J Acoust Soc Am 124:1838-1848. CrossRef Medline

Casseday JH, Ehrlich D, Covey E (1994) Neural tuning for sound duration: role of inhibitory mechanisms in the inferior colliculus. Science 264:847850. CrossRef Medline

Casseday JH, Ehrlich D, Covey E (2000) Neural measurement of sound duration: control by excitatory-inhibitory interactions in the inferior colliculus. J Neurophysiol 84:1475-1487. Medline

Chen GD (1998) Effects of stimulus duration on responses of neurons in the chinchilla inferior colliculus. Hear Res 112:142-150.

Covey E, Faure PA (2005) Neural mechanisms for analyzing temporal patterns in echolocating bats. In: Auditory signal processing: physiology, psychoacoustics, and models (Pressnitzer D, Cheveigné A, McAdams S, Collet L, eds), pp 251-257. New York: Springer.

Covey E, Kauer JA, Casseday JH (1996) Whole-cell patch-clamp recording reveals subthreshold sound-evoked postsynaptic currents in the inferior colliculus of awake bats. J Neurosci 16:3009-3018. Medline

Deatherage BH, Evans TR (1969) Binaural masking: backward, forward, and simultaneous effects. J Acoust Soc Am 46:362-371. CrossRef Medline

Denes P (1955) Effect of duration on the perception of voicing. J Acoust Soc Am 27:761-764. CrossRef

Ehrlich D, Casseday JH, Covey E (1997) Neural tuning to sound duration in the inferior colliculus of the big brown bat, Eptesicus fuscus. J Neurophysiol 77:2360-2372. Medline

Elliott LL (1962a) Backward and forward masking of probe tones of different frequencies. J Acoust Soc Am 34:1116-1117. CrossRef
Elliott LL (1962b) Backward masking: monotic and dichotic conditions. J Acoust Soc Am 34:1108-1115. CrossRef

Faure PA, Fremouw T, Casseday JH, Covey E (2003) Temporal masking reveals properties of sound-evoked inhibition in duration-tuned neurons of the inferior colliculus. J Neurosci 23:3052-3065. Medline

Frederiksen E (1977) Condenser microphones used as sound sources. Bruël Kjær Tech Rev 3:3-23.

Fremouw T, Faure PA, Casseday JH, Covey E (2005) Duration selectivity of neurons in the inferior colliculus of the big brown bat: tolerance to changes in sound level. J Neurophysiol 94:1869-1878. CrossRef Medline

Fuzessery ZM, Hall JC (1999) Sound duration selectivity in the pallid bat inferior colliculus. Hear Res 137:137-154. CrossRef Medline

Gadziola MA, Grimsley JM, Faure PA, Wenstrup JJ (2012) Social vocalizations of big brown bats vary with behavioral context. PLoS One 7:e44550. CrossRef Medline

Hind JE, Goldberg JM, Greenwood DD, Rose JE (1963) Some discharge characteristics of single neurons in the inferior colliculus of the cat. II. Timing of the discharges and observations on binaural stimulation. J Neurophysiol 26:321-341. Medline

Irvine DR, Gago G (1990) Binaural interaction in high-frequency neurons in inferior colliculus of the cat: effects of variations in sound pressure level on sensitivity to interaural intensity differences. J Neurophysiol 63:570 591. Medline

Leary CJ, Edwards CJ, Rose GJ (2008) Midbrain auditory neurons integrate excitation and inhibition to generate duration selectivity: an in vivo whole-cell patch study in anurans. J Neurosci 28:5481-5493. CrossRef Medline

Lu Y, Jen PH-S (2003) Binaural interaction in the inferior colliculus of the big brown bat, Eptesicus fuscus. Hear Res 177:100-110. CrossRef Medline

Pollack GS, Hoy RR (1979) Temporal pattern as a cue for species-specific calling song recognition in crickets. Science 204:429-432. CrossRef Medline

Rose JE, Gross NB, Geisler CD, Hind JE (1966) Some neural mechanisms in the inferior colliculus of the cat which may be relevant to localization of a sound source. J Neurophysiol 29:288-314. Medline

Sayegh R, Aubie B, Faure PA (2011) Duration tuning in the auditory midbrain of echolocating and non-echolocating vertebrates. J Comp Physiol A Neuroethol Sens Neural Behav Physiol 197:571-583. CrossRef Medline

Sayegh R, Aubie B, Fazel-Pour S, Faure PA (2012) Recovery cycle times of inferior colliculus neurons in the awake bat measured with spike counts and latencies. Front Neural Circuits 6:56. Medline

Semple MN, Aitkin LM (1979) Representation of sound frequency and laterality by units in central nucleus of cat inferior colliculus. J Neurophysiol 42:1626-1639. Medline

Tan ML, Borst JGG (2007) Comparison of responses of neurons in the mouse inferior colliculus to current injections, tones of different durations, and sinusoidal amplitude-modulated tones. J Neurophysiol 98: 454-466. CrossRef Medline

Zook JM, Casseday JH (1982) Origin of ascending projections to inferior colliculus in the mustache bat, Pteronotus parnellii. J Comp Neurol 207: 14-28. CrossRef Medline 